\title{
BARRIERS TO ACCESS: FOOD BANKS IN OUTER-RING GTA SUBURBS
}

\author{
by \\ Georgia Luyt \\ B.A. Hons., York University 2010 \\ A Major Research Paper \\ Presented to Ryerson University \\ In partial fulfillment of the requirements for the degree of \\ Master of Planning \\ in \\ Urban Development
}

Toronto, Ontario, Canada, 2014

CGeorgia Luyt, 2014 


\section{Author's Declaration}

I hereby declare that I am the sole author of this MRP. This is a true copy of the MRP, including any required final revisions.

I authorize Ryerson University to lend this MRP to other institutions or individuals for the purpose of scholarly research.

I further authorize Ryerson University to reproduce this MRP by photocopying or by other means, in total or in part, at the request of other institutions or individuals for the purpose of scholarly research.

I understand that my MRP may be made electronically available to the public. 


\title{
BARRIERS TO ACCESS: FOOD BANKS IN OUTER-RING GTA SUBURBS
}

\author{
(C)Georgia Luyt, 2014 \\ Master of Planning \\ in \\ Urban Development \\ Ryerson University
}

\begin{abstract}
Poverty in Greater Toronto Area suburbs is growing at an alarming rate, particularly in the wake of the 2008 recession. One associated outcome is a dramatic increase in residents' use of food banks. Suburban planning and design makes car ownership necessary to navigate these areas. How, then, do low-income residents address the barrier of transportation when accessing a food bank if they do not have a car? The investigation used qualitative research including a literature review, collection and analysis of data on food banks in the GTA, and interviews with food bank managers and front line workers. The results revealed that reduced access to a car, hours of operation of food banks, and the cultural difference between food bank users and donors in the suburbs are key areas for both long term and short term strategies that could ease the burden of transportation for food bank participants.
\end{abstract}

Key Words: suburbs; GTA; food banks; transportation; urban design; newcomers 


\section{Acknowledgments}

Sincere thanks go to Dr. Joseph Springer, who has been the ideal supervisor. His expertise, encouragement and ability to motivate is deeply appreciated. The energy and care he put into helping me craft my paper was invaluable.

I would also like to thank Ronald Keeble, my second reader. His advice, generosity with his time and knowledge on the subject were key in the writing of this paper.

I am very lucky to have a supportive and encouraging network of family and friends. Particular thanks go to Olivia for her keen eye for subordinate clauses and superfluous commas. And to Hakim, whose sense of humour kept me sane - for things too many to list, I am deeply grateful. 


\section{Terms and Definitions}

GTA refers to the Greater Toronto Area.

OAFB refers to the Ontario Association of Food Banks, a membership organization that advocates for and supports food banks across the province.

Throughout this paper, I refer to suburban residents, rather than citizens. This is a conscious choice for two reasons. First, not all suburban residents are citizens, but they are still served by food banks and other social services. Second, as residents also pay property taxes, they have the right to any and all municipal services, regardless of citizenship status.

In addition, I have used participants and clients interchangeably to refer to residents who use the food banks' services. This is an important choice of term, as it focuses on the food bank's need to serve people, rather than emphasizing people as dependent or needy. 


\section{Table of Contents}

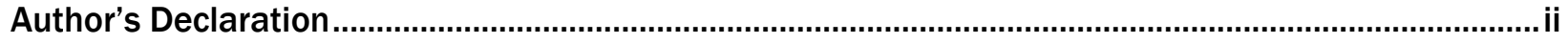

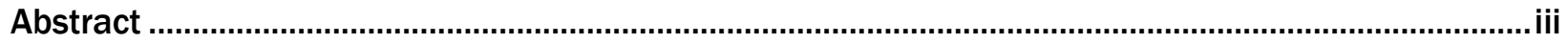

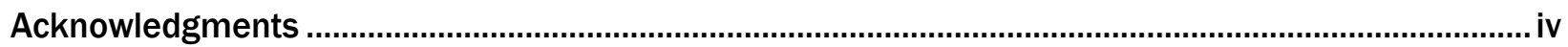

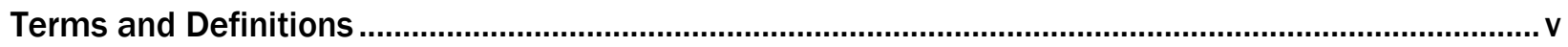

List of Figures ............................................................................................................................... viii

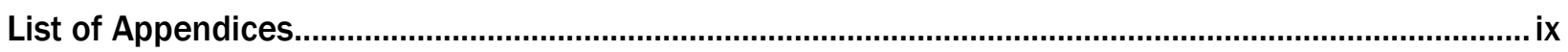

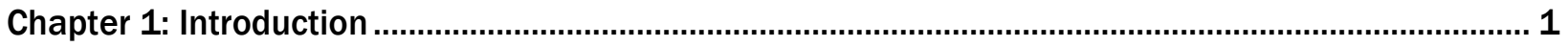

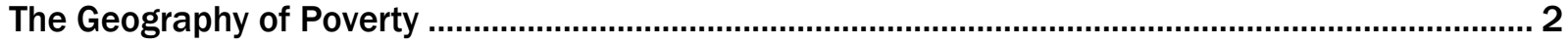

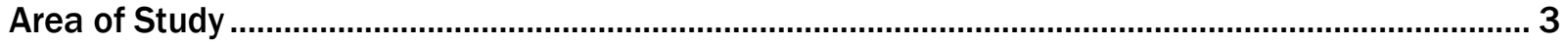

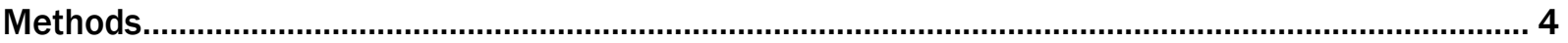

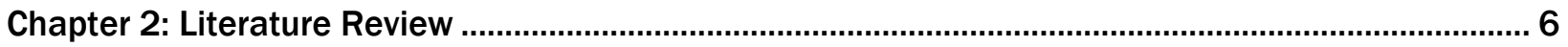

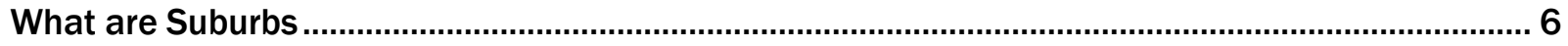

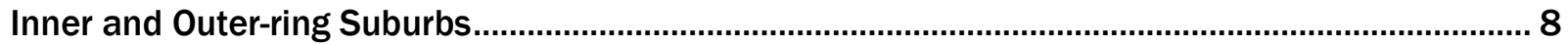

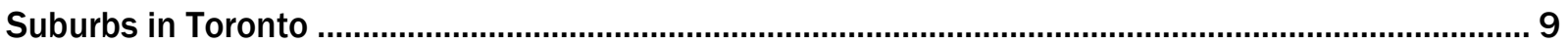

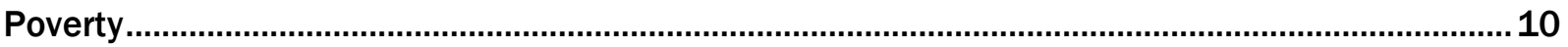

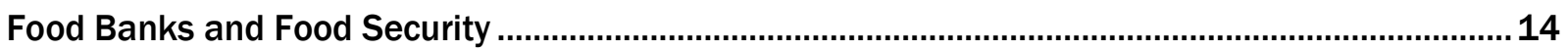

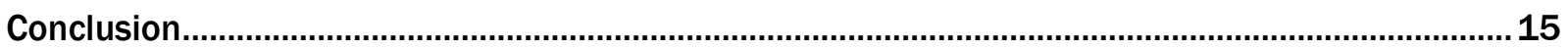

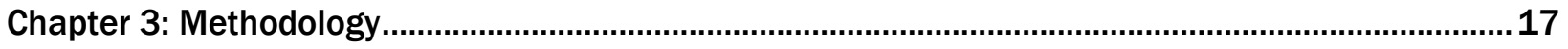

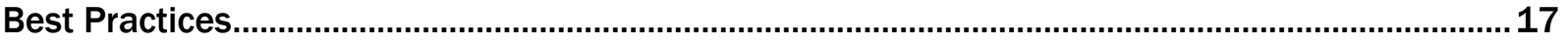

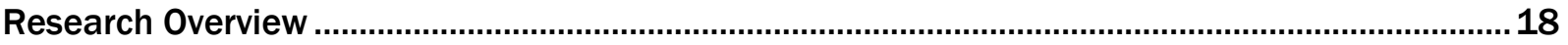

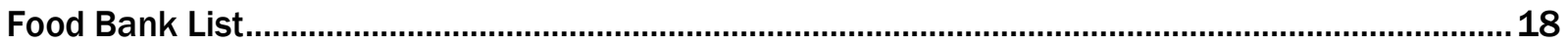

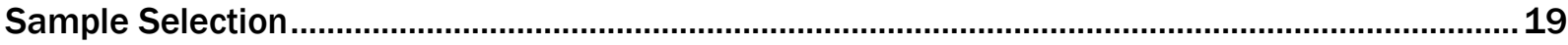

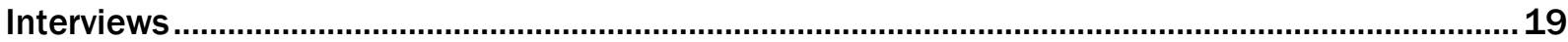

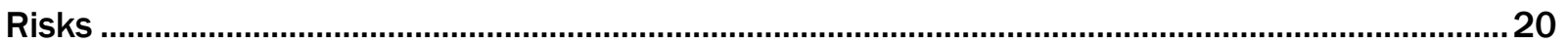

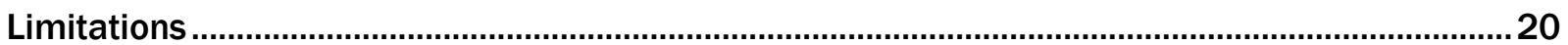

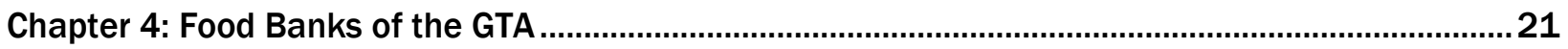

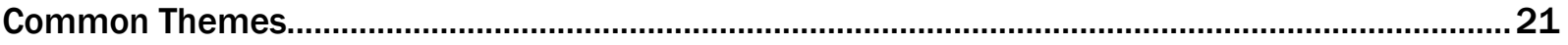

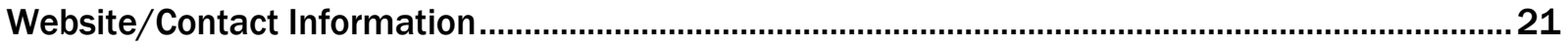

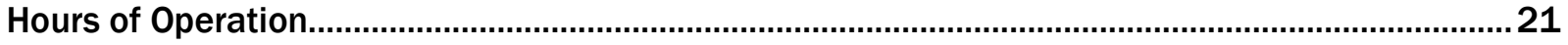

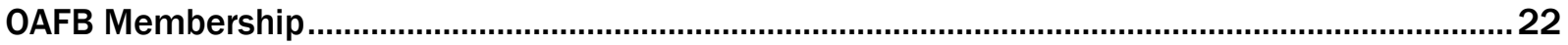

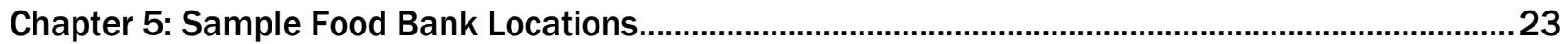

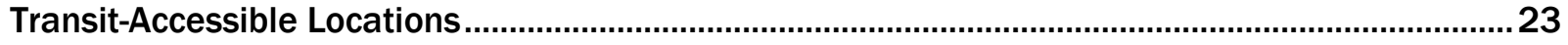

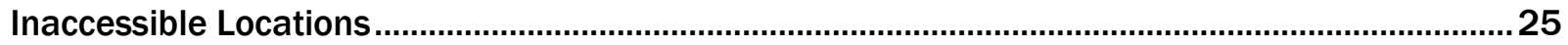




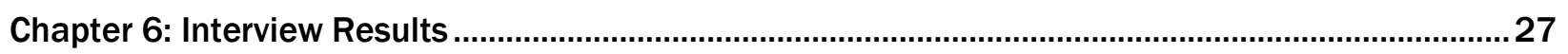

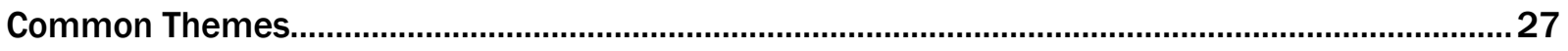

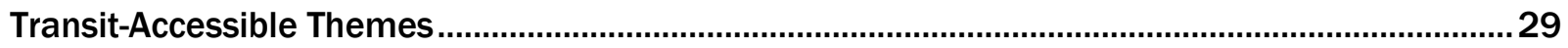

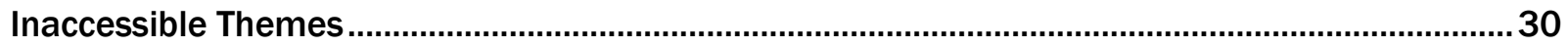

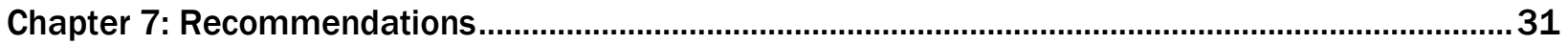

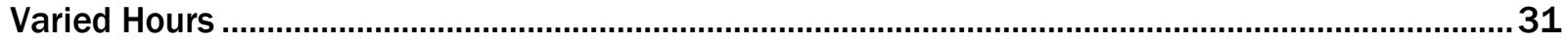

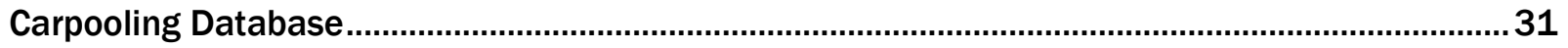

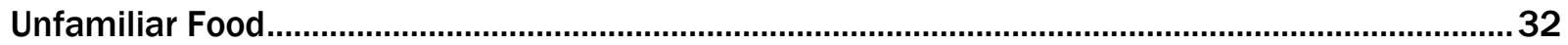

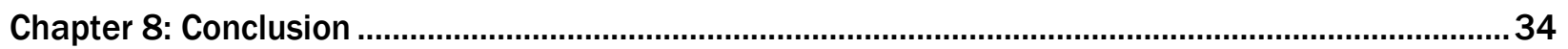

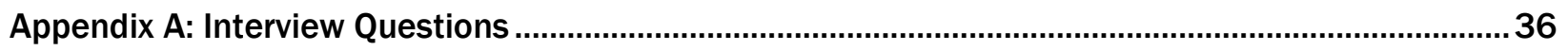

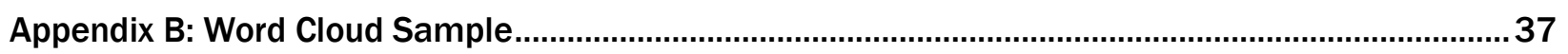

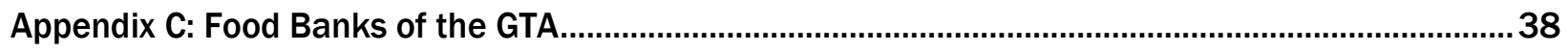

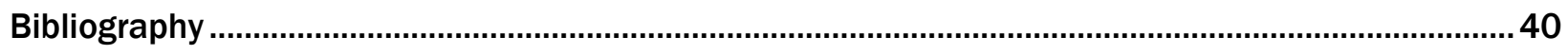




\section{List of Figures}

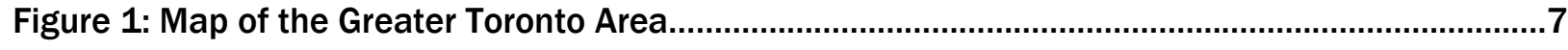

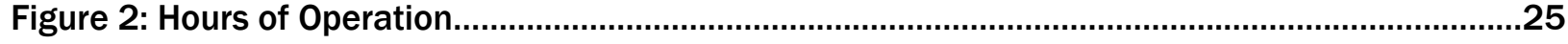

Figure 3: Brampton Salvation Army Food Bank in GTA Context ......................................................26

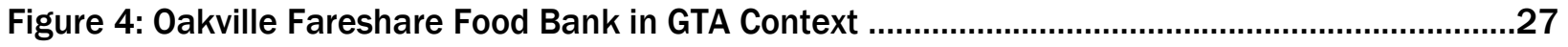

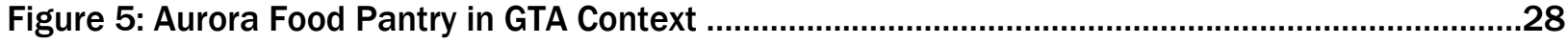




\section{List of Appendices}

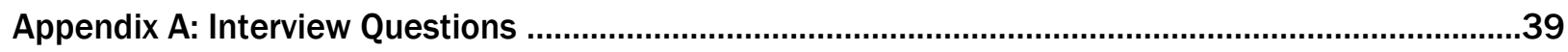

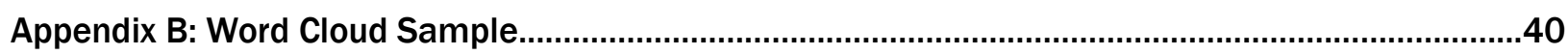

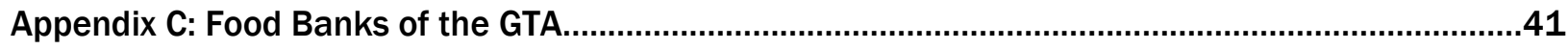




\section{Chapter 1: Introduction}

Poverty in urban centres is widely studied in urban planning and well-understood by the public. A newer phenomenon, in both academic study and general knowledge, is suburban poverty. Suburbs are traditionally painted as sites of affluence, conformity, and middle class lifestyles - the "doctors, lawyers and business executives" who "all play on the golf course" in Pete Seeger's 1962 satirical song Little Boxes. But suburbs are no longer, and have only seldom been, areas of wealth and privilege.

According to 2006 Census data, some suburbs in the Greater Toronto Area have poverty rates approaching that of downtown Toronto (Social Planning Toronto, 2012). A lack of affordable housing in the urban core pushes low-income residents to search elsewhere, often in suburbs. While downtown areas have readily available public transportation and social services, suburbs are not built to facilitate access to these essential public goods (Hulchanski, 2006).

Newcomers to Canada often gravitate to cities. While they may wish to settle in the downtown, where there are appropriate support systems for them, the lack of affordable housing means they must look elsewhere for housing (Preston, et al., 2009). Suburbs are now populated with middleclass and low-income Canadians, but also with newcomers from all over the world. As a result, these areas require services that address poverty and settlement issues.

One of the biggest challenges for low-income populations is finding adequate food for themselves and their families. Food banks are one way in which society has responded to this problem, and many suburban food banks have seen a sharp increase in use, particularly in the wake of the 2008 recession. The Ontario Association of Food banks has reported that there is also a high number of children and young adults using food banks in suburbs -reports show that more 0-24 year olds use food banks in Toronto's suburbs than in the city itself (Daily Bread Food Bank, 2013).

This paper examines the challenges facing low-income suburban residents who use food banks. It focuses on how residents deal with the lack of affordable, reliable transportation in suburbs, but also looks at issues of newcomer settlement and how issues of culture and identity play out in food banks. I have chosen to focus on the outer-ring suburbs of Toronto, and rely primarily on qualitative research methods, including a literature review, one-on-one interviews with food bank workers, and data collection on food banks across the GTA. I will discuss what barriers participants face in traveling to and using the food bank, what solutions have been implemented and what solutions food banks are considering to reduce these barriers. 
Food banks are a useful and important lens through which to examine issues of access to social services in suburbs. They are a service that requires clients to carry a significant amount with them at the end of an appointment - this makes transportation a particularly salient issue.

While there has been little formal research in this area, interviews showed that overcoming the transportation barrier is on the minds of food bank workers across the GTA. While the issue of suburban poverty, and food bank use in suburbs, is gaining momentum in the public consciousness, it still requires detailed and thorough analysis. Through this MRP, I aim to provide an understanding of one aspect of poverty in suburbs in the hope that it will add to the broader conversation around transportation and equity in suburbs.

\section{The Geography of Poverty}

Urban poverty is the subject of extensive research within the urban planning field, and there is a general understanding of this issue among the public at large. Unfortunately, there is less focus on, and understanding of, poverty in suburbs. Historically, the suburbs were built for the growing middle class as an escape from the noise, pollution and social ills of the urban core. As a result, the built form and social infrastructure were not designed to accommodate the needs of low-income people. For example, there is less rental housing available in suburbs, and the separation of residential uses from businesses and activity centres means that you must drive a car to move through the suburbs.

The assumption of suburbs as sites of affluence, reinforced through popular culture, continues to the present day, but this no longer reflects the reality of many suburbs. There is a "hidden" poverty in the suburbs. For example, low-income newcomers may couch-surf instead of using homeless shelters, or they may divide their children among the houses of several friends or family members (Preston, et al., 2009). Some residents buy large detached homes, and move in with their extended family in order to cover their costs. While they may live in a typical suburban home, and appear to be living a typical suburban life, their situation is very different from the idealized image of suburban living.

In her book Perverse Cities, Pamela Blais writes that without access to a car, suburban residents can experience "an exclusion from many activities" because suburbs are not designed to be navigated on foot and access to public transit can be limited (Blais, 2010 p.29). In an area designed for driving, the exclusion that residents face without a car is compounded by a public transportation system that has been designed around the needs of the commuter. The timing, frequency and routes of public transportation aim to ease movement for workers who need to 
access the urban core, often on a typical 9am to $5 \mathrm{pm}$ work schedule. This design does not consider those who need to move through their neighbourhood at other times of day and do not own a car, or those who work different hours.

This research examines the challenges of providing social services in a suburban setting. While there is a substantial branch of academic study on service delivery in downtown locations, there is significantly less work that focuses on social services in the suburbs. The research that does exist often focuses on health services generally, rather than food banks specifically. As a result, my research provides a glimpse at how food banks are experiencing, and trying to remedy, the challenges specific to the suburbs. By focusing on food banks, I hope to spark a conversation about how to combat the transportation barrier, and explore methods that could apply to other social services in suburbs.

Transportation is not only a barrier for suburban food banks, it can be a barrier for clients of urban food banks as well. For example, the cost of public transit may be too high for some participants. Urban food banks have a relatively simple solution to this problem: they can subsidize transit costs for participants. Once the financial barrier is removed, the transit system is generally reliable enough to take them where they need to go. Unfortunately, covering the cost of transportation in the suburbs would only partially address the challenges facing food bank participants. Common suburban challenges such as walkability and infrequent or unreliable transit would still remain as barriers for clients. Other solutions must be put in place to address the vast distances clients may have to travel in order to arrive at the food bank, and a transit system that is not designed with their needs in mind.

\section{Area of Study}

In this paper, I focus on outer-ring suburbs of the Greater Toronto Area (GTA), which include the Regions of Peel, York, Halton and Durham. These areas have experienced population booms in the last two decades, and make up some of the fastest growing municipalities in Canada (Ministry of Finance, 2013). They are also dealing with growing poverty rates, as well as the settlement issues which face newcomers in any municipality. The City of Toronto has a history of delivering social services to the urban poor. This research investigates how social service providers deal with the built form, transportation system and lack of walkable neighbourhoods in suburbs outside the City of Toronto's jurisdiction.

It was important to study outer-ring suburbs instead of inner-ring suburbs because inner-ring suburbs are still serviced by the same transportation system and governed by the same municipal 
council as the downtown core. Residents in outer-ring suburbs face daily struggles with suburban transportation providers and municipal councils, and it is important to see how these differences impact their ability to access food banks.

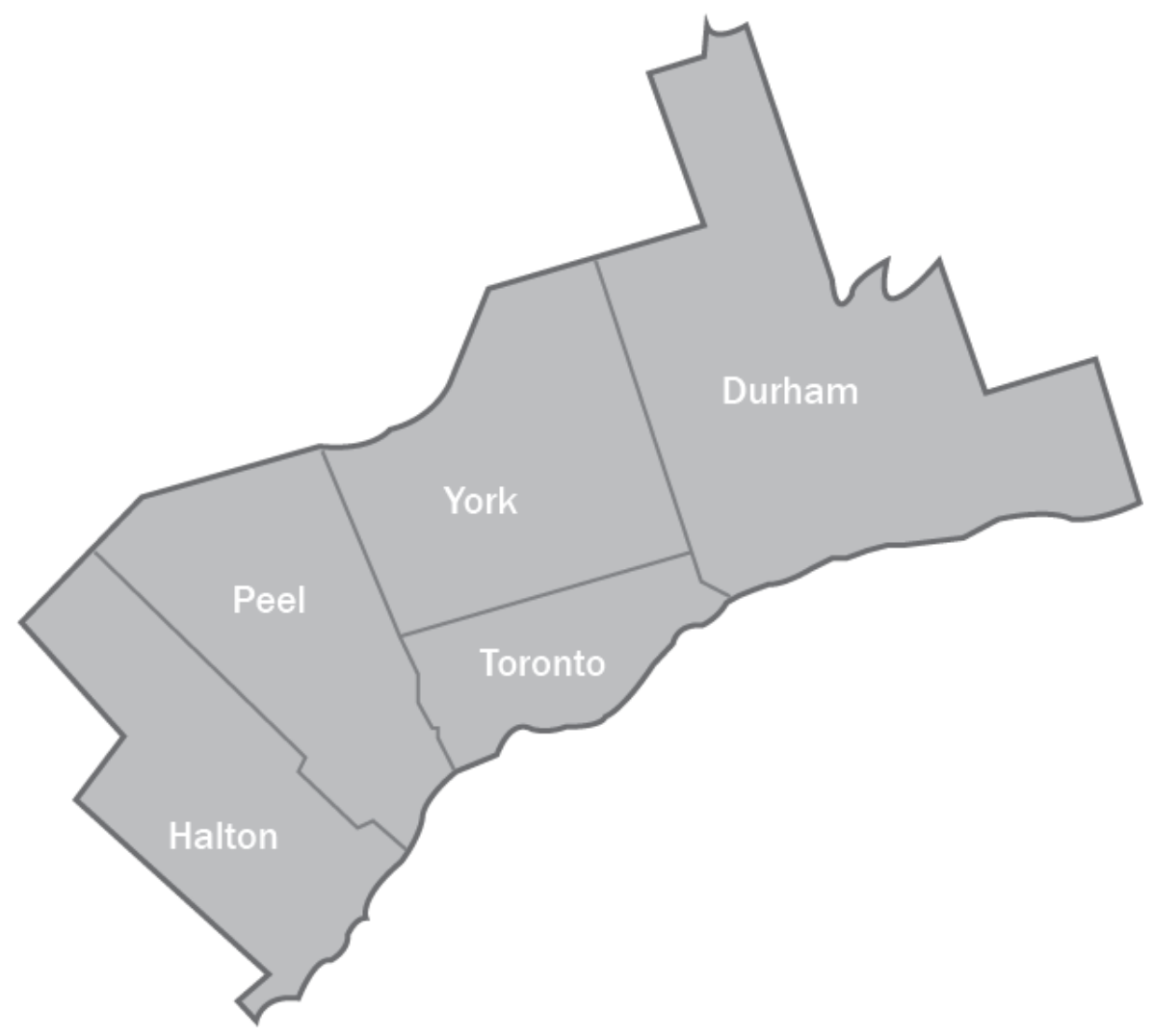

Figure 1. The Greater Toronto Area

\section{Methods}

In addition to primary data collection and secondary research, I have relied on one-on-one interviews to gain insight on how suburban food banks are dealing with their clients' transportation challenges. I spoke to workers from three different food banks across the area of study - two of the locations were within walking distance of reliable public transportation, and one was located along an infrequent bus route, and deemed inaccessible. I interviewed managers of food banks to establish the challenges the food bank faces from a high level, as well as any solutions they have implemented to address those challenges. I also spoke with front-line workers in food banks, to understand how issues of transportation affected food bank clients. The result is a mixed methods approach that combines these methods of data collection and analysis. One of the limitations of this study is that I did not speak to food bank clients themselves. In addition, the subjects I 
interviewed do not have the opportunity to interact with people who cannot overcome barriers and are unable to travel to the food bank. As such, they were unable to elaborate on the challenges that outright prevent people from traveling to a food bank. Both of these limitations could serve as avenues for future research. 


\section{Chapter 2: Literature Review}

This section will explore some of the common themes and background of this paper. It will examine what makes suburbs distinct from the urban core - their physical design, their residents, and how social services are delivered there. It will also touch on what distinguishes an inner-ring suburb from an outer-ring one and look at Toronto's suburban growth from the post-War era to the present.

This section will also discuss poverty, how it is measured in Canada, and what it means to be a lowincome suburban resident, specifically in the outer-ring suburbs. Finally, it will examine the history and current use of food banks and highlight some challenges that come with delivering social services in the suburbs.

\section{What are Suburbs}

Although there is some consensus on what suburbs are, there is disagreement among academics on how to define them. Some definitions are based on location or built form, some on access to transportation and other services, while others are based on the cultural and social dynamics of the neighbourhood (Forsyth, 2012). One of the first challenges in the study of suburbs is that there is no clear method for defining a suburb. Ann Forsyth (2012) has found two distinct ways of defining what a suburb is: one is based on what a suburb has, or is (is low-density, has scattered land uses) while the other is based on what a suburb lacks, or is not (not a city, lacking diversity). Forsyth concludes that the best way to move forward and avoid the murky concept of suburbs is to be more explicit about the type of suburb one is discussing. By referring specifically to density, access to transportation infrastructure, distance from an urban centre, or age of the settlement, readers can gain a more in-depth understanding of the type of neighbourhood under discussion. The following is a broad overview of the physical design, social services and types of residents in suburbs, as well as an explanation of the difference between inner-ring and outer-ring suburban neighbourhoods.

\section{Physical Design}

Suburbs are primarily car-dependent spaces and have a marked separation of uses, characterized by large malls with surface parking lots (Dunham-Jones \& Williamson, 2011) (Garreau, 1991). Homes are not generally located within walking distance of office and retail uses. Instead, residents must often drive to access the destination malls or office parks in the area. Suburban homes tend to be single family dwellings and are often built in groups by the same developer, which can result in a similar aesthetic for houses in the same neighbourhood (Dunham-Jones \& Williamson, 2011). The residential streets of suburbia are often curvilinear, rather than forming a grid pattern, and there are many culs-de-sac. The few residential roads which do lead to major 
arterial roads encounter high speed auto traffic spread out over a large number of lanes. (DunhamJones \& Williamson, 2011) This lack of connectivity often makes navigating suburban neighbourhoods difficult and time consuming, particularly for someone without a car.

Suburbs are often associated with sprawl, which is also a somewhat contentious term. Sprawl can be defined as a process of "specific and dysfunctional growth", often characterized by high rates of car ownership, low rates of walking or cycling, and a high rate of pollution (Erwing, Pendall, \& Chen, 2002 p.1). While there may be some degree of sprawl in the inner city and in inner-ring suburbs, it tends to be less dramatic than in outer-ring suburbs. Suburban sprawl results in low residential densities which can have an adverse impact on people's physical activity. Many daily errands are easier to access by car than they are on foot, and the absence of eyes on the street feeds a cyclical disincentive to walk (Forsyth, Oakes, Schmitz, \& Hearst, 2007). In particular, residential proximity to retail spaces is associated with a higher likelihood of walking. The prevailing separation of uses in the suburbs means that people may be less likely to walk (Rodriguez, Evenson, Brines, \& Diez Roux, 2009). The physical design of suburbs not only discourage physical activity, but also means that there are greater distances to cover to get from residential areas to other destinations than there are in the urban core.

\section{Social Services}

Studies indicate that social services are less accessible in suburbs than in urban cores. In fact, there is a worrying trend towards stratification of services between urban cores and suburbs. Many suburbs are under-served, while urban cores tend to have both higher levels of service and better access to services (Fincher, 1999). The separation of land uses which characterizes suburbs can also mean that social services are housed in malls. Throughout North America, libraries, retirement residences, and even City Halls have chosen to locate near, or, in fact, in, suburban shopping malls (Garreau, 1991). The separation of residential land uses from commercial (and, as a result, social service) land uses "makes it highly impractical to rely on transit to reach most destinations" (Filion, 2003 , p. 1). The physical design of suburbs also impedes access to social services for suburban residents. If access to shopping malls requires access to a car, then in many suburbs receiving social services also requires a personal vehicle (Garreau, 1991).

\section{Suburban Residents}

One way to understand suburbs and their residents is to look at academic literature. Classic scholarship defines suburbs as sites of homogeneity, with a high concentration of high-income residents, and a close relationship with and access to nature (McManus \& Ethington, 2007). Revisionist scholars, on the other hand, assert that suburbs have a more complex relationship with 
the urban core. They point out that some suburbs have a significant numbers of jobs, retail and office space, and some areas may have more ethnic and cultural diversity than the urban core they surround (McManus \& Ethington, 2007). This work, including writings by Joel Garreau and Robert Fishman, shows that scholars are developing a more nuanced understanding of how suburbs function and interact with urban centres. Their work is useful in analyzing the suburbs of Toronto, many of which have different densities, land use separations and office space from the prototypical suburb.

Media images of the suburbs tend to portray them as white, middle-class spaces, with very little interruption of this narrative (Muzzio \& Halper, 2002). The portrayal of suburbia as either a centre of conformity and cultural homogeneity, or as the ideal living choice for families is entrenched in popular culture in North America, but is not based in the reality of twenty-first century suburbs these areas tend to be quite multicultural and multi-ethnic (Huq, 2007) (Lee \& Hall, 2010). Even the common perception of suburban living as a choice based on lifecycle is inaccurate..$^{1}$ In the United States, non-family households outnumbered family households by 2000 , and a quarter of those households with children had a single parent (Lee \& Hall, 2010). In fact, American suburbs are also seeing higher growth rates in middle and older age demographics than they are in families (Lee \& Hall, 2010).

In a study based on the 2000 U.S. Census, researchers found that most suburbs had more diversity than the city centre based on measures including race, level of education, income and residential tenure (Lee \& Hall, 2010). In addition, assumptions about the choice to live in the suburbs as owing to lifecycle were found to be incorrect; many senior citizens choose to remain, or even move, to the suburbs (Teaford, 2008). Clearly, common assumptions about who lives in the suburbs are incorrect.

\section{Inner and Outer-ring Suburbs}

Further complicating any definition of a suburb is that these growths on the outskirts of urban centres have come in distinct waves which have impacted the urban form, access to services, and governance. Suburbs tend to fall into two categories: inner-ring and outer-ring. Inner-ring suburbs are usually those built between 1940 and 1965 - often spurred on by a combination of higher incomes and increased car use in the city, which facilitated further distances between the home and places of work, etc. (Lee \& Leigh, 2005) (Sewell, 2009). While many start as separate

\footnotetext{
${ }^{1}$ Choosing to live in the suburbs is often explained as a choice based on one's stage of life (i.e. lifecycle). For example, young families may choose to reside in the suburbs to raise children. It is often assumed that once the children grow up and leave the family home, the parents will downsize and relocate closer to the urban core.
} 
municipalities from the urban core, they are sometimes amalgamated (as in Toronto) in an effort to streamline services, promote economic growth and cohesion, and to expand the municipality's tax base (Kitchen, 2002). Inner-ring suburbs tend to have a lower population density than the urban core. However, amalgamated inner-ring suburbs have strong ties to the urban core through politics, taxation, and services such as education and transportation.

In contrast, outer-ring suburbs are newer, and are often outside the border of even an amalgamated city. Sometimes referred to by Joel Garreau's term 'edge cities', outer-ring suburbs are characterized by very recent, low density housing developments, a strong separation of land uses (housing, retail or industrial), and physical design that necessitates owning a car (Garreau, 1991). The population density can be much lower than in the city center; While the City of Toronto has a population density of 4,150 persons per square kilometer, outer-ring municipalities such as Pickering and Oakville have densities of 383 and 1,314, respectively (Statistics Canada, 2012).

\section{Suburbs in Toronto}

John Sewell's The Shape of the Suburbs traces the boom in suburban development to the postWorld War 2 era, where returning soldiers and their families settled in Toronto along with some 750,000 new immigrants from Europe (2009). This sudden rise in population and demand for housing affected suburbs near the core of the city (such as Willowdale and Newtonbrook) but also areas that remain outside the city today, such as Thornhill and Richmond Hill (Sewell, 2009)

As with many post-war suburbs, Toronto's inner and outer suburbs were designed for a particular family structure: one parent, usually the father, working 8 hours a day, with a mother staying in the home to raise 2-4 children who could be entertained in the private home with a large lot (Hulchanski, 2006). In Toronto, strong patterns of development in what are now outer-ring suburbs started in the 1970s with the Toronto-Centered Region Report. This report attempted to address forecasted growth by steering residential development along Lake Ontario's shores, where costs of infrastructure would be lower (Filion, 2003). However, the opening of a sewage system in 1973 in the Regions of York and Durham, allowed cheaper development in those areas (Filion, 2003). Due mainly to attention from environmental activists, planning documents in the late 1980s and early 1990s started to encourage development that would concentrate around denser nodes to enable a higher modal split with transit, walking and cycling (Filion, 2003). However, the 1995 provincial election of the Progressive Conservative Party meant that funding for these projects dried up, leaving suburban municipalities with no support to change existing patterns of development (Filion, 2003). Although more recent GTA suburbs have passed planning documents to encourage dense, transit-oriented development, many continue to permit the traditional, low-density development 
that is already so pervasive (Blais, 2010) (Ministry of Infrastructure, 2006). In fact, the outer-ring suburbs of the GTA are still not fully built. New subdivisions and developments are still being built on greenfield (undeveloped) land (Lakey, 2014).

Both poverty and newcomer settlement are on the rise in North American suburbs. In the United States, one third of suburban population growth between 2000 and 2009 came from newcomer populations (Suro, Wilson, \& Singer, 2011). This is due in part to the lack of affordable housing in urban cores as well as the settlement patterns of new immigrants. Newcomers often join members of the same ethnic or cultural origin who have already established themselves in suburban communities. In the Greater Toronto Area, many immigrant communities are choosing to settle in suburban communities, rather than the downtown area. In 1996, for example, Chinese Canadians made up almost $20 \%$ of the population of Richmond Hill, a city in York Region, while in Toronto they accounted for only $7 \%$ (Preston \& Lo, 2000). In fact, by $2006,43 \%$ of York Region's population were newcomers to Canada, with the majority coming from India, China and Pakistan (Preston, et al., 2009). Along with concerns about the environmental impacts of sprawl and political decisions from higher levels of government, Toronto's status as a major destination for newcomers has shaped the growth of its suburbs.

\section{Poverty}

\section{Poverty in Canada}

Defining poverty has been a challenge in Canada, as the government has never mandated a single measure of poverty. The three main measures of poverty include the Low-Income Cut-Off (LICO), the Low Income Measures (LIM) and the Market Based Measure (MBM). The LICO is designed to show the point at which individuals will experience financial difficulties, while the LIM represents half of the median family income. Finally, the MBM reflects the price of a combination of goods and services that are necessary for good physical health. Statistics Canada uses the LICO in their data and reports, as it indicates how many people are "substantially worse off than the average" (Statistics Canada, 2014). It is difficult to even attempt to alleviate poverty when different government bodies, community organizations or charities are using inconsistent methods to measure poverty.

Despite differences in measurement of poverty, it is clear that income inequality has been growing steadily in Canada. Analysis of wages in Canada indicates that the richer are getting richer, while the poor are getting poorer. One tool for such an analysis is the Gini coefficient, a common measure of income equality. It calculates a score between 0 , which indicates a perfectly equal 
distribution of income, and 1, which indicates complete inequality (Hunter, Sanchez, \& Douglas, 2012). Canada's Gini score 1990 was 0.388 , and by 2009 it was 0.462 (Hunter, Sanchez, \& Douglas, 2012). This marked change indicates that the gap between rich and poor is steadily increasing. With this knowledge, it is crucial that those in poverty have the services they need, regardless of whether they live in urban, rural or suburban settings.

\section{Poverty in the Suburbs}

Suburbs are commonly imagined as predominantly white, middle-class spaces. Cultural products, particularly film and television shows, tend to portray this as the universal suburban experience (Muzzio \& Halper, 2002). Films are a critical source of shared knowledge in North American culture, and the majority of contemporary films will only present slight deviances from this norm (Muzzio \& Halper, 2002). Very few challenge the image of the suburbs by showing the realities of the growing poverty that is being documented in cities across North America (Dreier, 2004). Demographic shifts have changed what is the traditional understanding of suburbs as wealthy places - all is not as it seems in suburbia.

Rather than being exclusively white spaces, many suburbs have substantial newcomer populations. A common experience, particularly in American cities was 'white flight', where middle class residents left the inner city for outlying suburbs, leaving low-income, and often racialized, residents in the downtown area. (Madden, 2003). Suburban relocation by urban residents is longer the defining source of suburban population growth, particularly in the GTA. In $2006,48 \%$ of residents of Mississauga (an outer-ring suburb in Peel Region) reported a non-official language as their mother tongue, which included Tagalog, Urdu, Polish and Punjabi (City of Mississauga, 2013). This number is higher than the Toronto CMA average of $42 \%$, indicating that there are proportionally more newcomers in an outer-ring suburb than in the urban core (City of Mississauga, 2013).

The problem of suburban poverty appeared in newspapers as early as the 1960s; a 1964 article for The Washington Post indicates that, at that time, two-thirds of Washington's low-income residents lived in the suburbs (Gilliam \& Dewar, 1964). Newspapers such as the The New York Times and The Globe and Mail have been writing steadily about poverty in the suburbs since the early 2000 s.

Since the recession of $\mathbf{2 0 0 8}$, extensive discussions of poverty in suburbs have emerged, with some publications running extensive series, and local papers reporting on the topic in-depth.

Recent work by non-governmental organizations (NGOs) has highlighted rising poverty rates in GTA suburbs. Social Planning Toronto's Action on Poverty Report (2012) examined poverty and housing issues in each federal riding in the GTA using 2006 Census data. Their report found that the federal 
ridings of Markham-Unionville and Mississauga Cooksville (both in outer-ring suburbs) have poverty rates approaching Toronto's levels (Social Planning Toronto, 2012). While the report does not indicate growth rates of poverty in these areas, they provide useful comparisons of individual ridings to the region's average in each area.

The economic recession of $\mathbf{2 0 0 8}$ has been a significant factor in the rise of suburban poverty. In the years following 2008 , many social services and food bank associations have noted a spike in the need for assistance among suburban residents. Recent professional reports indicate growing poverty in GTA outer-ring suburbs. According to the Children's Aid report Child Poverty in the GTA, between 1997 and 2008, Peel and York Regions have seen significant increases in child poverty, by $51 \%$ and $44 \%$ respectively. While many suburbs still have wealthy residents, this growth in suburban poverty is alarming. It can lead to two classes of people within suburbs - one which has financial security, is well-connected to the urban core and also has access to whatever they need anywhere in the metropolitan region, and another which has less financial security, and as a result is less connected to services and amenities throughout the region (Fincher, 1999).

One of the strongest factors in the push away from the urban core and towards the suburbs is the lack of affordable housing. David Hulchanski's (2006) work on income distribution in Toronto has shown a marked decrease in affordable housing in the core, and geographic polarization of income in the city as a result. Hulchanski shows that when low-income households were located in the core of the city they had ample access to transit and services. Now, as the vast majority of lowincome residents in Toronto live in suburbs, they have much less reliable access to these essential public goods (Hulchanski, 2006). This shift indicates a disappearing middle class where residents are forced out of their neighbourhoods due to gentrification and higher market values of property, leading them to find housing away from key supports that are more easily available in the core of the city (Hulchanski, 2006). Similar patterns have occurred in outer-ring suburbs, where the number of middle income households has decreased, creating two distinct groups of high income and low income households (Hulchanski, 2006). The high prices of housing in urban cores have pushed many new immigrant communities to settle in outer-ring suburbs. While newcomers to Canada may wish to remain downtown where there are appropriate support systems for them, the lack of affordable housing means they must look elsewhere for housing (Preston, et al., 2009).

Although low-income populations are moving to the suburbs due to lack of affordability in the urban core, this does not mean that housing is significantly cheaper in these areas. There is a lack of rental and social housing in these areas that often leads to multiple or extended families sharing housing, or living in unlicensed rental units (Preston, et al., 2009). While many low-income and 
newcomer residents in outer-ring suburbs are in precarious housing situations, the poverty is hidden from view because the housing stock looks similar and there is low use of shelters (Preston, et al., 2009). Affordable housing is seen as a prerequisite to successful settlement for newcomers; a lack of affordable housing in a suitable neighbourhood prevents newcomers from having a safe base from which to build a new life (Preston, et al., 2009). While the houses in outer-ring suburbs have a higher price, market forces such as taxes and development charges have established a situation in outer-ring suburbs where larger homes are cheaper than in the urban core (Blais, 2010). This means that extended families (such as a nuclear family, uncles and grandparents) can live in one house, reducing the cost burden of housing.

'Core housing need' is a Canadian Mortgage and Housing Corporation (CMHC) term, which refers to housing which does not pass the adequate, affordable or suitable test (CMHC, 2010). The CMHC defines adequate housing as a home that does not require any repairs, affordable housing as a home that costs less than $30 \%$ of household income, and suitable housing as a home that has sufficient bedrooms for the family's makeup (CMHC, 2010).

In 2010 (the most recent data available), Toronto Census Metropolitan Area (CMA) had a significantly higher than average core housing need at $18 \%$, compared to Canada's average of $13 \%$ (CMHC, 2013). In Peel Region, core housing need was at $15.6 \%$, in York Region it was 13\%, and in Durham, 12\% of households were in core need (City of Toronto, 2011). While Toronto's percentage of core need is higher than the outer areas of the GTA, the growth of core need has been much faster in the suburbs than in the city. Toronto's growth rate of core housing need between 1991 and 2006 was 57\% while Peel, York and Durham's were 162\%, 247\% and 79\% respectively (City of Toronto, 2011). Clearly, core need is growing at an extremely rapid rate in the outer suburbs - this is an issue must be addressed.

While being a low-income resident in a city is unquestionably a challenge, proximity to social services and access to transit to get to these services increases this population's access to muchneeded support systems. The cost barrier to transit access can be solved (provided the organization has sufficient funds) by giving transit tokens to program participants. In the outer-ring suburbs, this access is nowhere near as readily-available. When services are concentrated in malls and public transit is unreliable, low-income suburban residents must make difficult decisions about how they will find support.

One of the biggest challenges for low-income populations is getting adequate food to feed their household. Food banks are one way to address these challenges, with some providing meals, 
bundles of non-perishable foods, and a chance to socialize with other members of the community. While the particular reasons for needing to access a food bank differ from client to client (loss of job, family breakup, disability or serious illness), the "widespread lack of income to cushion hard times is the key factor" in people's use of food banks (Food Banks of Canada, 2013 p.13). In fact the average monthly income for a GTA household using a food bank is $\$ 693$ (Daily Bread Food Bank, 2013). In addition, the percentage of suburban residents under 24 years old who use food banks is higher in the outer-ring suburbs of Toronto than in the core or inner-ring suburbs (Daily Bread Food Bank, 2013). The rising poverty in the suburbs has been resulted in an increased use of food banks, a shift which will be explored below.

\section{Food Banks and Food Security}

While systems of food distribution for low-income residents have been in place since the 1930s, primarily in places of worship, Canada's first official food bank only opened in 1981 (Edmonton's Food Bank, 2013). As a result of rising rates of poverty, community activists worried that lowincome populations would not have adequate food. This was a departure from the public, government-funded support traditional of the welfare state, as food banks ran on a charity model of donations and distribution. Since the first food bank opening over 30 years ago, the number of users has increased significantly. A Food Banks of Canada report indicates that, in 2013, 833,000 Canadians used food banks each month (Food Banks of Canada, 2013) (Scharf, Saul, \& Levkoe, 2010). The same report indicates that of that number, 375,000 of those users were from Ontario, and $35 \%$ of them were children (Food Banks of Canada, 2013). Although the number of Canadian food bank users has dropped since 2012, the report indicates that the number of clients has been consistently higher post-2008. For example, Ontario's food bank use increased by $19 \%$ between 2008-2013 (Food Banks of Canada, 2013).

Food banks have historically been a needs-based program - eligibility to receive food is largely based on income as well as residence in a catchment area (Saul \& Curtis, 2013). However, determining eligibility can become an embarrassing and demoralizing process for applicants, and some food banks are attempting to eliminate some of the negative associations with food banks for their clients. Departing from a focus on food for subsistence, food banks have started to promote the idea of food security (Saul \& Curtis, 2013). Food security refers to a person's ability to have enough affordable, culturally appropriate and fresh food accessible to them. The Toronto Food Policy Council (1998) highlights the difference between looking at people as consumers or as citizens. While consumers are given the rights to accept or reject a product based on their ability to pay, citizens are considered a part of society, with inherent rights and responsibilities. Treating 
participants as citizens rather than consumers also means shifting the concept of food away from commodities and towards an understanding of its crucial role in promoting health and a sustainable environment (Welsch \& MacRae, 1998). As citizens, people have the right to adequate nutrition that is healthy and easily accessed. Food banks that concentrate on promoting food security often expand their programming to urban agriculture, meal preparation, farmers' markets and community development. While this is a pro-active step to improving people's experience in a food bank, much of this programming is best suited to urban fabrics, with easy access to transportation and walkable communities. This type of programming does not easily translate to suburban food banks that encounter challenges merely with providing basic services to clients (Saul \& Curtis, 2013). The following is an examination of some of the challenges associated with service delivery in suburbs.

Researchers looking at service delivery in the suburbs found that one of the biggest difficulties clients experience is in trying to reach the location (Francis, Berger, Giardini, Steinman, \& Kim, Pregnant and Poor in the Suburb, 2009) (Preston, et al., 2009). The growing number of food bank users in Ontario (and in the suburbs in particular) necessitates a thorough discussion of techniques to aid service delivery.

Having to travel distances to access social services such as food banks impedes people's abilities to work, volunteer their time or invest it with family. In the case of participants with a disability or severe illness, these long distances can prevent them from accessing services entirely (Fincher, 1999). While the call for 'spatial affirmative action' with regard to service delivery in outer-ring suburbs is timely, it will likely be up to social service agencies themselves to address this issue. They will need to be creative to ensure that their services reach those most in need (Fincher, 1999). Although there has been little research on issues of access as it relates to food banks, research on access to suburban health services may provide some clues to the areas which could be addressed by food banks. In one study, people who weren't able to access health services in outer-ring suburbs cited a lack of knowledge about service options, language barriers, lack of transportation and lack of social network (Francis, Berger, Giardini, Steinman, \& Kim, 2009). Barriers such as lack of knowledge, perceived discrimination and a lack of social network may also be applicable to prospective food bank clients in outer-ring suburbs.

\section{Conclusion}

If access to social services is dependent on ability to arrive at a mall, or another central business location, then in the absence of a car the suburban resident must consider public transportation. Unfortunately, suburbs are designed to be used by cars, a fact which encourages individuals to 
travel to their destinations in solitary vehicles (Garreau, 1991). Trying to implement public transportation other than commuter rail can prove challenging. The design of the streets, low density in residential areas, and distance from urban centres contribute to an area that is quite difficult to serve, because it is difficult to design bus routes that will have enough users to be financially viable (Garreau, 1991). The low residential density results in destinations that are far apart from each other, as well as further walking distances for residents to get to a bus stop (Transportation Cooperative Research Program, 1999).In addition, the traditional method of public transportation planning in suburbs means that there will be peaks of transit use (e.g. residents going to work during rush hour) and periods with very little use - this presents transit providers with a challenge of providing enough service during peaks, and also maintaining routes during low-use periods (Transportation Cooperative Research Program, 1999). These obstacles to efficient transit result in challenges for suburban residents who wish to access clustered social services without access to a car.

The lack of services and transit in inner-ring suburbs of Toronto is exacerbated in outer-ring suburbs, by public transit that tends to be focused around traditional commuter patterns rather than the needs of shift workers or residents who need to move around the city at other times of day. In fact, the assumption that suburbs are middle class spaces may make poverty worse, as these areas are not seen as priorities for policies and programs that would alleviate poverty (Francis, Berger, Giardini, Steinman, \& Kim, 2009).

As a response to poverty, food banks present one solution to the growing income inequality in the outer-ring suburbs. However, the lack of connectivity and reliable public transportation in these areas may make service delivery more challenging than it is in the city. The research for this paper will look for tools and techniques to be used by outer-ring food banks to serve their clients in the face of this challenge. 


\section{Chapter 3: Methodology}

\section{Best Practices}

While there is a substantial branch of academic study on service delivery in downtown areas, there is significantly less work that focuses on social services in the suburbs. The research that does exist often focuses on health services generally, rather than food banks specifically. As a result, the method is informed principally on local and international studies that examine health service delivery generally, rather than food banks specifically in suburbs.

Research on social services in the suburbs principally relies on qualitative methodologies. These methods tend to be more flexible, since they allow interviewees to relay information they deem to be important. They also give a rich depth of knowledge that might otherwise be missed, and provide a helpful illustration of broader trends in society (Francis, Berger, Giardini, Steinman, \& Kim, 2009). Key informant interviews conducted with service providers or with those using the service, are quite common. For example, one study looking at racialized pregnant women trying to access pre-natal services in a New York City suburb used a qualitative model of semi-structured focus groups with service users to determine the barriers they face in terms of accessing these services. Their findings indicate that lack of access to reliable transportation and the prohibitive costs of housing near health services were two of the largest barriers to accessing health services for pregnant women in these areas (Francis, Berger, Giardini, Steinman, \& Kim, 2009). Another study examined the hidden poverty of the suburbs, and the barriers precariously housed newcomers face in using shelter and housing services (Preston, et al., 2009). This study used a similar method to Francis et al, with semi-structured interviews but instead used service providers as key informants instead of newcomers themselves.

Qualitative research is based on the idea that what you say reflects what you think- and that people's words reveal an underlying intention and meaning. Discourse analysis is a popular method employed to analyze the content of qualitative interviews and focus groups. It is used to analyze how people understand their realities, and how they speak about them. For example, discourse analysis was used to evaluate the responses of interviews focusing on postpartum health care for suburban residents in Tanzania (Lugina, Christennson, Mbekenga, \& Olsson, 2010). Due to its flexibility of use, and limited use of resources, discourse analysis was employed to analyze the transcripts of interviews. Once interviews have taken place, the content of those interviews is analyzed, often using patterning software. Discourse analysis often examines structures of what is being said, word choice and pattern, and tries to derive a deeper meaning from words (Fairclough, 1995). Although there is no strict approach when conducting discourse analysis, it is designed to 
allow for inference, interpretation, and analysis of language used by research participants (Fairclough, 1995).

Other types of inquiry into of service delivery include field visits, where researchers observe, and take notes on, the content of interactions in the service provision centre (Lugina, Christennson, Mbekenga, \& Olsson, 2010). This methodology has the advantage of observing encounters as they happen, instead of having to ask about them in interviews or focus groups. However, it also requires a significant amount of resources to conduct effectively, both in terms of time and researchers. As a result, content analysis was deemed too labour-intensive for the research process.

Due to the exploratory nature of this research, one-on-one interviews were conducted and analyzed with thematic analysis and word clouds.

\section{Research Overview}

In order to investigate how food banks deal with clients in the suburbs, a comprehensive list of food banks in GTA suburbs was compiled primarily through Internet research. The list was analyzed for how accessible each location was based on hours of operation, whether they had a website, and number of days they were open including weekends. Then, sample locations were selected based on their access to transit, and semi-structured interviews were held with service providers and front line workers to gain an understanding of what kinds of programming these locations offer, and how they are received by food bank clients. The content of the interviews was analyzed using discourse analysis.

\section{Food Bank List}

In order to select sample locations for interviews, food banks were grouped for by Region: York, Durham, Halton and Peel. Food banks were found through the Ontario Association of Food Banks member lists, Google searches, and social services databases in each GTA Region.

The number of days each location was open per week was recorded, along with whether they were open in the morning, daytime, or evening. Morning was defined as any time before 10am, daytime as between $10 \mathrm{am}$ and $5 \mathrm{pm}$, and evening as $5 \mathrm{pm}$ or later. This was done to assess how accessible the food bank might be to clients who have schedules other than the traditional 9-to-5 work week. The total number of days each location was open per week was also noted, to form a clearer idea of how frequently services are offered. The food bank's web presence was measured since a website can be a key place where interested people could look for further information about 
programming, eligibility for services, or directions. The food bank list was the basis of sample selection for the interview and analysis of the research.

\section{Sample Selection}

Interviews were conducted with volunteers who work at three sample food banks in GTA suburbs. Sampling choices were made based primarily on the availability of transit within a walkable distance: transit-accessible was determined as being within $600 \mathrm{~m}$ of the nearest transit stop. 'Inaccessible' locations were chosen for being further than $600 \mathrm{~m}$ from the nearest transit stop or along a route that had stops less than once per hour. This was based on an analysis of walkability done in Halton Region, which estimates suburban walkability as between 400 and $800 \mathrm{~m}$, depending on "land use mix, street connectivity, density...buffers to moving traffic, and pedestrian crossings," among other factors (Nosal, 2009). The 600m distance was also relevant as many food bank users are those with reduced ability to walk long distances such as seniors, those requiring mobility devices, and families with young children.

Samples were chosen from across the region, but were also based on availability of the food bank employees. I contacted mangers of the sample locations by email to request an interview with themselves and one of their front line workers (or volunteers). They were asked to post a flyer in the food bank to recruit a front line worker/volunteer who would participate in an interview. Interested parties could feel free to privately volunteer for the study. This provided an arm's length selection process, and ensured that employees or volunteers did not experience coercion to participate.

\section{Analysis of Sample Locations}

Information on sample locations was gathered based on their provincial ridings. It was important to understand the income level, child poverty rates, age, and immigration levels in each area in order to contextualize the challenges each location faced.

\section{Interviews}

Interviews were conducted principally in offices and food bank locations. It was important that the managers and front-line workers be from the same food bank - this allowed me to gain an understanding of the programming provided by management, and the response to that programming as observed by front-line workers. An application to Ryerson's Research Ethics Board (REB) was submitted and approved for interviews with key informants.

I recorded the interviews using written notes and audio-recordings so that information could be verified at a later date. The interviews were semi-structured in nature: I had a list of questions to be 
answered, but also allowed the conversation to flow in order to gain any other information that subjects felt was important to the study. The question list is included as Appendix A.

\section{Discourse Analysis}

The content of interviews was analyzed using principles of discourse analysis. In particular, I looked for repetition of words and themes throughout individual interviews, and across interviews. I used Wordle, a free Java-based online tool that creates word clouds to identify commonly-used words and concepts. Interviews with transit-accessible locations were compared to interviews with inaccessible locations and analyzed for any key differences as well as common themes. A sample word cloud is included as Appendix B.

\section{Risks}

This research was deemed to be of minimal risk by the REB. While it did require front-line workers to evaluate the progress of their employers in confronting barriers to access, the information was kept confidential and any analysis was stripped of identifiable details. At the end of the interview, each subject was asked if there was anything they wished to strike from the record. Additionally, no coercion or deception occurred as part of the study. As such, there is a minimal chance for repercussions following the interview process.

\section{Limitations}

The limitations of this research generally fall into two categories: sample size and choice of interview subject. The number of sample locations is limited to three due to limitations of time and resources; research was conducted solely by a student researcher.

Although qualitative research is not dependent on sample size for valid results, the small number of sample locations is a limitation in the context of the Greater Toronto Area. Further research will be required to explore and broaden the themes identified in this paper.

The choice to interview food bank managers and front line workers was made in order to get an understanding of what programs are offered and observations of how clients respond to those programs. However, this line of research would benefit from interviewing food bank clients themselves to discover their opinions, and glean recommendations from them. 


\section{Chapter 4: Food Banks of the GTA}

\section{Common Themes}

In order to understand the number and coverage of food banks in the GTA, I compiled a list of all the food banks in the area through Internet research (Appendix C). I identified a list of common themes which could inhibit or encourage better access to food banks in the suburbs. The four themes that appeared were: the ease of finding contact information and location; the location's hours of operation; membership in the OAFB; and proximity to transit. While each of these themes could be studied in detail, I chose to base my sample selection on access to transportation, which I will discuss further in Chapter 5 . The three remaining themes are discussed briefly below.

\section{Website/Contact Information}

In compiling the list of food banks, I tried to keep in mind how a potential client could find information about them, assuming that if they did not have access to region-specific social service lists on paper, they would look online. For each food bank, I identified the primary method of contact they cited (whether phone or email) and kept track of their web address, if they had one. This is relevant to discussion of access because without a website or email address, prospective food bank clients may have difficulty gaining information about opening hours, eligibility requirements, and even directions to the location.

I found food banks in several different ways: through regional lists provided by social service agencies or the municipality, from online search engines, or through the Ontario Association of Food Banks (OAFB). Of the food banks found in the GTA, 33\% of the food banks listed did not have a website. Locations that did not have websites most often did not have an email address listed, either. While those with a website usually included an email address, most had a phone number to call to make appointments.

\section{Hours of Operation}

The hours that a food bank is open will determine how many people it can serve, and whose schedule it can accommodate. Food banks in the GTA have quite varied hours of operation and number of days open. For example, $48 \%$ of locations were only open one or two days per week. This can limit the amount of people who have access to the food bank and can also force clients to fit into narrow availability. Further, only $22 \%$ of food banks were open on at least one weekday evening or weekend. This is of concern for groups like the working poor, those who struggle to have enough to eat despite also having a job. The number of working poor in the GTA has risen by $42 \%$ between 2000 and 2005, with significant growth in outer-ring suburbs like Markham, Richmond 
Open for business: GTA food banks

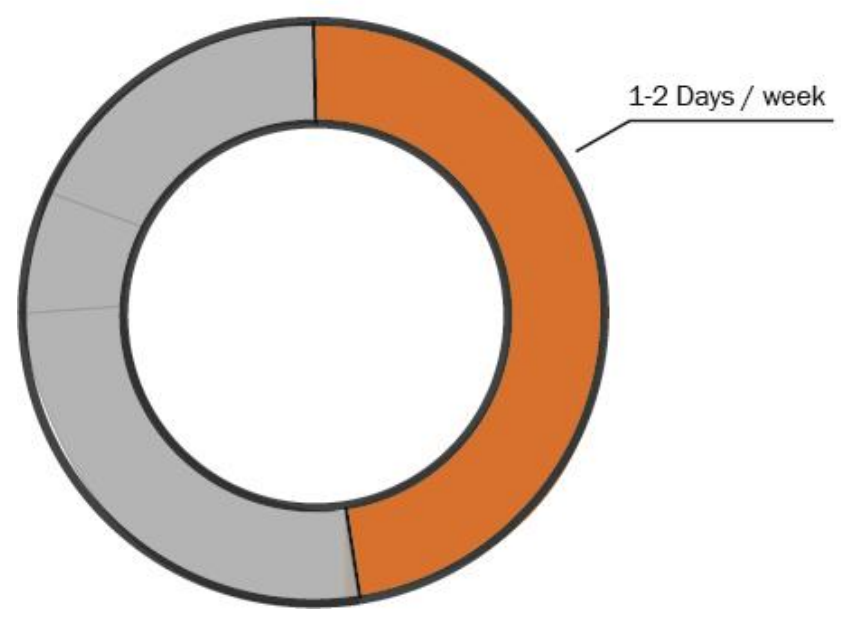

Hill and Mississauga (Stapleton, Murphy, \& Xing, 2012). If food banks are only open during regular business hours of 9am to $5 \mathrm{pm}$, it will be difficult or impossible for anyone who is working these hours to access their services.

Figure 2. Hours of Operation

\section{OAFB Membership}

The Ontario Association of Food Banks (OAFB) has 120 member food banks in the GTA. The OAFB offers members access to a national food sharing program, food handling certification, as well as reduced liability and property insurance. Members must be registered charities, and must adhere to their Code of Conduct. Membership in the OAFB allows food banks an extra means of building awareness of their location, as the OAFB website lists its member organizations along with contact information. The OAFB only allows one member food bank in each community, without any geographic overlap (OAFB, 2012) Of the GTA food banks found, 9 were members of the OAFB. This means that 39 others have to pay upfront to give volunteers and employees safer food handling practices, improve awareness of their location, and pay higher levels of insurance. OAFB membership may not be feasible for some food banks, due to cost or geographic location, but joining the OAFB might help locations to formalize training and reduce some incidental costs. 


\section{Chapter 5: Sample Food Bank Locations}

\section{Transit-Accessible Locations}

Both sample locations had at least one bus stop within $600 \mathrm{~m}$ from their front door. In fact, both of the sample locations were within $200 \mathrm{~m}$ of at least one bus stop. While scheduled frequency and reliability remain issues in accessing transit, close proximity to a bus route was deemed a distinct advantage in allowing low-income clients alternatives to private vehicles if they needed to access the food bank.

\section{Location 1}

The first location is the Brampton Salvation Army Food Bank, located in the Brampton-Gore-Malton riding, in Peel Region. In this riding, $22 \%$ of children live in poverty, significantly higher than the $19 \%$ overall in Brampton (Social Planning Network of Ontario, 2012). Two of the major social issues facing the area are unemployment and a high number of newcomers (Social Planning Network of Ontario, 2012).

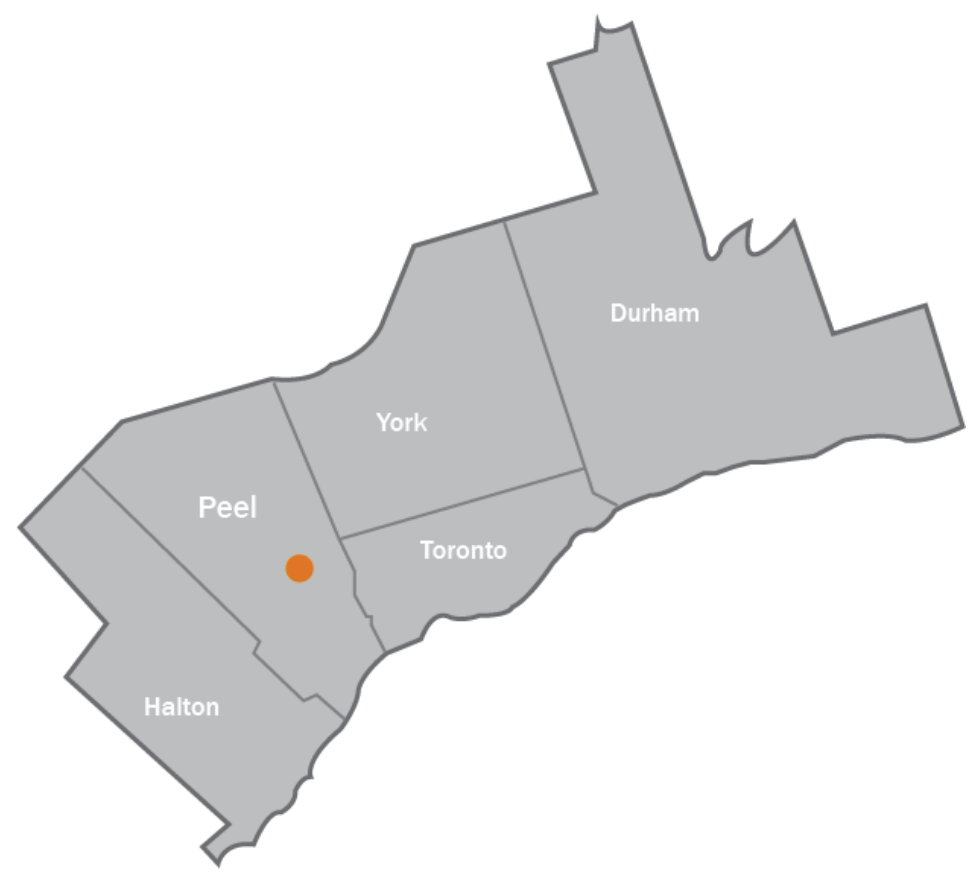

Figure 3: Brampton Salvation Army Food Bank in GTA context

The Brampton Salvation Army Food Bank is located within 200m of two bus lines, making it a fairly transit accessible location. The bus routes run from Humber College to the Brampton Gateway Terminal, and from the Westwood Mall terminal along Torbram Road, a major arterial in Brampton. 
The food bank is open between 9am and $4 \mathrm{pm}$, Monday to Friday, and is run on an appointmentonly basis. The food bank tailors its food basket based on a budget assessment it does on intake with clients. Its catchment area encompasses Brampton, Malton and Caledon, and it serves between 800 and 1000 households per month. The food bank has a small staff, and is otherwise run by volunteers and students.

\section{Location 2}

The second location near transit is the Oakville Fareshare Food Bank, in Halton Region. It is located in the Oakville riding, and $10 \%$ of its residents live in poverty, compared with $8.5 \%$ in Halton Region. At $12 \%$, the proportion of Oakville children in poverty is comparatively lower than Brampton's, but it is higher than Halton's overall level of $10 \%$ (Social Planning Network of Ontario, 2012). The small number of residents in poverty is of concern, as it can lead to the poverty being more hidden and thus unaddressed. Food banks and other social services are crucial in areas such as this to ensure that low-income residents are not forgotten.

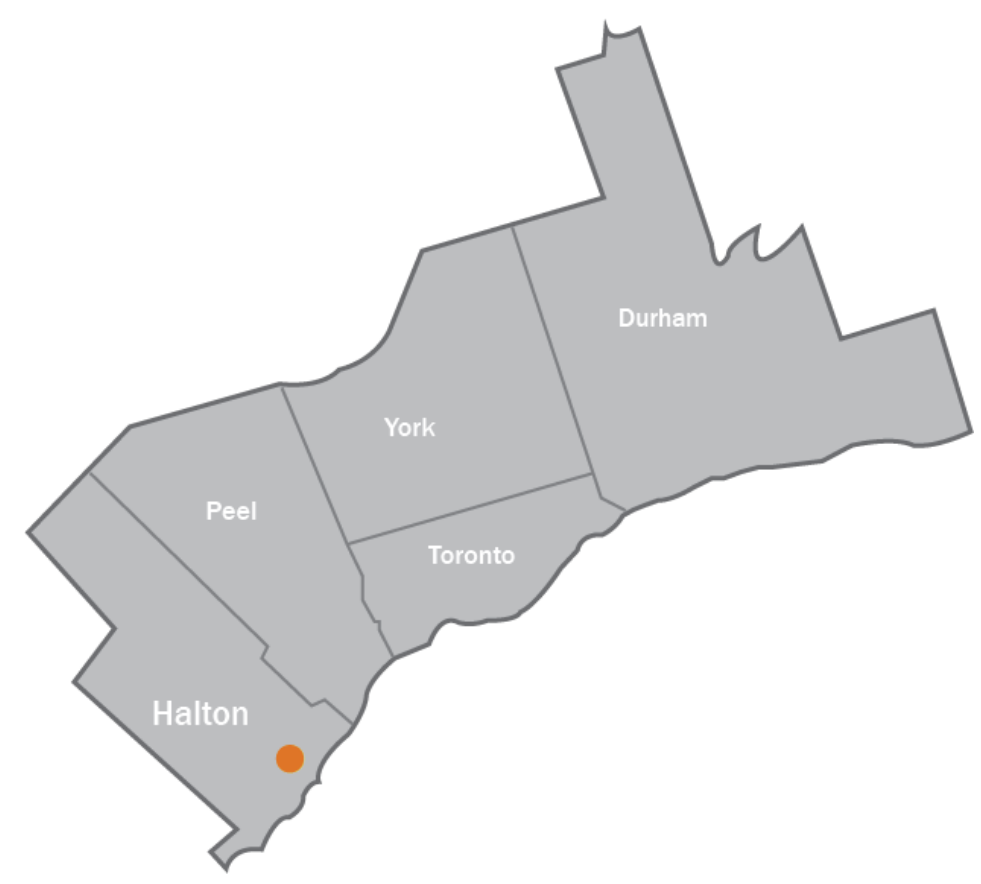

Figure 4: Oakville Fareshare Food Bank in GTA Context

The Oakville Fareshare Food Bank is located near one bus route that links the nearest GO station with Sheridan College and the Uptown Core transit terminal. The food bank is open Mondays from $10 \mathrm{am}$ to $2 \mathrm{pm}$ and Thursdays from $3 \mathrm{pm}$ to $7 \mathrm{pm}$. It is run entirely by volunteers, and relies on donations from food drives and grocery stores. While the Oakville Fareshare focuses on delivering 
food to clients, it is also affiliated with a free cooking class to help newcomers cook with food they may not have encountered before. The food bank serves between 350 and 400 households every month.

\section{Inaccessible Locations}

Food banks were deemed inaccessible if they were further than $600 \mathrm{~m}$ from the nearest bus stop, or along a transit route that ran less frequently than once an hour during the food bank's hours of operation. Infrequent bus service was included in the inaccessible sample as it is difficult to rely on, particularly if a client is carrying large amount of bags.

\section{Location 3}

The third location is the Aurora Food Pantry, which has been serving the community since 1990. It is mainly volunteer-run, and is open in the evenings and on weekends. In the Food Pantry's riding of Aurora-Newmarket, $9 \%$ of residents live in poverty (Social Planning Network of Ontario, 2012). While this is lower than the regional average of $12 \%$, the hidden nature of poverty may translate into fewer services for those who do need it (Social Planning Network of Ontario, 2012). In addition, Aurora-Newmarket has a higher percentage of rental tenants than the rest of the region.

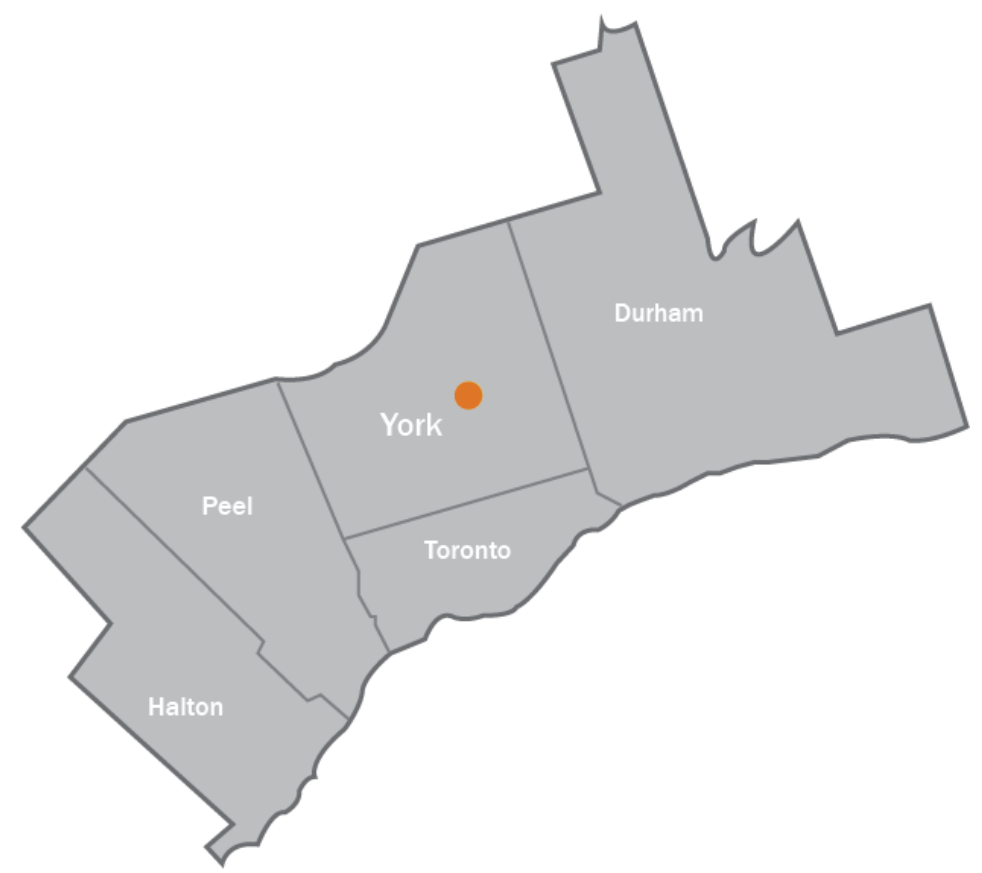

Figure 5: Aurora Food Pantry in GTA context

Although the Aurora Food Pantry is located within walking distance of a bus stop, the bus route is an infrequent one. As such, staff reported that very few clients use the bus service, and most choose to drive, carpool, walk, or cycle. The Food Pantry serves an average of $\mathbf{2 0 0}$ families per 
month, and is open to any resident of Aurora or Oak Ridges. It has recently moved from a central location in Aurora to a more remote, industrial location due to a lack of accessible entrances in the previous location. As a result, it has seen a shift in the travel patterns of participants. The Aurora Food Pantry is a member of the York Region Food Network, which emerged from a need to strengthen the resources of food banks in the region in response to growing poverty in the area. In addition, it is a member of the OAFB, and is experiencing a fairly recent change in client demographics; the Food Pantry has seen a sharp increase in newcomers visiting their location in the last 5 years. 


\section{Chapter 6: Interview Results}

Once interviews with food bank managers and front line workers were transcribed and formed into word clouds, several themes began to emerge. These themes have been categorized as common themes, themes from transit-accessible locations, and themes from the inaccessible location.

\section{Common Themes}

The following themes emerged from interviews with accessible and inaccessible food banks. The themes which related directly to transportation include: carpooling; consistency of transportation; catchment area; challenges for first-time clients; liability and insurance for delivery. Themes that were not directly related to transportation but were consistently discussed as challenges include: hours of operation and culturally appropriate food.

\section{Carpooling}

Carpooling is a very common method of getting to the food bank, as reported by managers and front line workers. Front line workers reported that when new clients start attending the food bank they will often organize their own transportation, sometimes relying on buses or taxis to bring them home with their groceries. Once clients have begun to form relationships with others at the food bank, they start making arrangements to carpool with new friends. For food banks which operate on an appointment basis, clients sometimes ask to schedule an appointment at the same time as their friends in order to better arrange transportation. This indicates that as clients forge social networks within the context of the food bank, they can develop strategies for dealing with the lack of transportation in suburban locations.

\section{Catchment Area}

One of the biggest differences between suburban food banks and urban food banks is the large catchment area in suburbs. The majority of sample food banks reported serving at least their own municipality; others accepted clients from multiple surrounding municipalities. Food banks in suburban locations may serve a similar number of people to their urban counterparts, but the low density of the suburbs means that this population is spread out over a larger geographic area. This has two consequences. First, clients may be travelling long distances in order to reach the food bank that serves them. Without a car, clients may be covering large distances using transit, walking or cycling. Second, the more limited nature of suburban transportation means that, even if a food bank is located near transit, it is quite possible that their clients may not be able to easily access transit from their own home. As a result, food banks serving large areas may need to support clients with transportation in ways that urban food banks do not need to address. 


\section{Consistency of Transportation}

Many clients use multiple modes of transportation to get to the food bank, both within the same trip and from visit to visit. For example, clients may have to walk great distances to get to the nearest bus stop that would take them to the food bank. They also may have access to a car for some visits, but have to use the bus or walk to the food bank for other visits. Although none of the food banks kept data on clients' mode of transportation, front line workers reported that clients would regularly alternate between carpooling, walking, and transit, depending on the resources available to them at the time of the visit. If clients could not access transportation at the times when the food bank is open, they may have to wait until the following week to find a time when transportation and food bank availability line up. This is a particular challenge for clients of food banks which operate on an appointment basis, as clients must find transportation for a narrow time window.

\section{Challenges for First-Time Users}

First-time users of food banks are often not prepared for the sheer amount of groceries they are given by the food bank. For example, one food bank gives its clients $\$ 350$ worth of food monthly for a family of four, which amounts to a full trunk load of an average sedan. First-time users who arrive by bus, bicycle, or walking with a bundle buggy are often ill-equipped to bring the full amount home using their initial mode of transport, and have to call a taxi. This is not an expense that food bank users can usually afford. Interviewees, and particularly front-line workers reported telling firsttime clients to be prepared for a large amount of bags, but clients often arrive unprepared nonetheless.

\section{Liability and Drivers' Insurance}

Many food banks have investigated how to start a driving service for clients. This could come in the form of a delivery service of groceries to the client's home, or a pick-up/drop-off service to bring clients to the food bank and take them back home with their groceries. Food bank managers mentioned two barriers to putting these programs in place. The first challenge was the cost; implementing a delivery service would mean paying for the operation of a vehicle, training volunteers, as well as the increased liability insurance for volunteers to drive clients. These costs were deemed too high for already stretched budgets. The second challenge is to ensure the personal safety of volunteers driving clients. These challenges have prevented the food banks in this study from implementing delivery programs.

\section{Hours of Operation}

A food bank's hours of operation will dictate how many people it can serve, as well as who can access the food bank. For example, those who work traditional 9am to 5pm hours will not be able 
to go to a food bank that is only open while they are at work. A food bank's hours of operation are, however, dependent on the resources available to each individual food bank. Locations that have identified a high number of clients who are working poor have tried to remain open past conventional working hours of $9 \mathrm{am}$ to $5 \mathrm{pm}$. Front line workers from food banks with later open hours noted a distinct difference in demographics of the clients using the food bank. Often, clients rushing from work would only arrive just before closing and the food banks would have to remain open past the designated closing time. This indicates a strong need to make sure that clients who work have opportunities to access the food bank, particularly if they are travelling from the urban core.

\section{Culturally Appropriate Food}

Participating food banks reported what is a growing trend in the suburbs - a high growth rate of newcomers into the area. This can present challenges with language barriers, if newcomer clients do not speak English or French. For example, managers reported intentionally looking for volunteers who spoke languages spoken by common newcomer groups. Front line workers reported challenges with conveying crucial information with newcomer clients, sometimes resorting to using online translators to communicate. The challenges that newcomers face in food banks also extend to the types of food that is available. Front line workers reported that newcomer clients are sometimes unfamiliar with the groceries handed out by the food bank. Responses to this challenge varied, but workers stressed that they do not feel they have a choice in their food, as the majority of it is donated. Food banks in areas with longstanding newcomer populations reported established strategies for communicating with clients despite language barriers, and starting to address food requests. In contrast, food banks in areas with more recent influxes of newcomers have not yet found a way to address these challenges.

\section{Transit-Accessible Themes}

Food banks close to transit tended to be in older suburbs - locations that have a high proportion of newcomers to Canada, as well as high levels of child poverty and unemployment. The following are themes that emerged mainly from these locations.

\section{Multi-Family Homes}

One of the most common trends seen in the settlement patterns of newcomers in the GTA is extended families living in the same house. This is a result of cultural norms of co-habitation, efforts to save money, and as a reaction to a lack of affordable rental stock in the area. Front line workers reported that these families tend to have an easier time arriving at the food bank than households with one nuclear family, as there is usually someone who can provide transportation to the food bank. Ironically, the living arrangements that increase the core housing need according to 
CMHC definitions can also be a source of support and strength when it comes to issues of transportation and accessing services.

\section{Cultural Difference}

Food banks located near transit were, by and large, more used to dealing with newcomers from many different countries. They had adopted strategies for dealing with language barriers (such as asking clients to bring translators, recruiting volunteers who could speak multiple languages, and using online translation tools to communicate with clients). These strategies mean that language barriers can be mitigated once the client is in the food bank. These locations had also started to adapt to food requirements of newcomers, with some providing Halal foods, or purchasing sausages made of chicken, rather than pork. Although managers and front line workers reported ongoing difficulties in terms of language and culturally appropriate food, they also stated that they felt their strategies were serving the needs of clients.

\section{Inaccessible Themes}

\section{Adjustments to Helping Newcomers}

The location with less frequent transit was unused to newcomer clients, as the area had only recently seen an influx of newcomers. This has led staff to face new language and cultural barriers when interacting with clients. The food bank reported that clients do not always know how to cook with food they are given, and that this has presented a challenge. Although culturally appropriate food is a necessary aspect of food security, this food bank relies almost exclusively on grocery donations, and so cannot always ensure that the food they receive reflects the priorities of their clients.

\section{Alternate Transit Options}

This location is in a municipality without a comprehensive transit system. While this means that mobility across the municipality can be limited, it also means that residents have access to alternate transit solutions, such as Dial-a-bus programs. Staff reported that clients could call for a bus service (operated by the municipality) to bring them to and from the food bank. Unfortunately, these services only operate on existing bus routes, and do not operate door-to-door. As a result, clients would need to get to the closest bus stop, both on the way to the food bank and on the way back, while carrying their groceries. Staff reported that, while this type of alternate transit option might be useful if clients lived near a bus route, this is not often the case. As a result, many clients have not opted to use this service, and instead rely heavily on carpooling or walking to the food bank. 


\section{Chapter 7: Recommendations}

Any recommendations for food banks must first and foremost consider the lack of funding that these service providers face. In making recommendations, I have tried to chose solutions that could re-allocate resources, or take a minimal amount of extra resources to execute. Some recommendations provide a short-term and long-term solution, to reduce the initial impact of changes to the food bank.

\section{Varied Hours}

The hours a food bank is open will determine who is able to access its' services, but the number of hours it is open is also a function of its ability to pay staff or recruit enough volunteers to serve clients. Adjusting hours of operation presents a strategic opportunity for suburban food banks to address the needs of the working poor. It would reduce the burden on some of the most vulnerable clients that food banks have: singles and single mothers, who may not have any other family members who can access the food bank while they are at work. Addressing the number of hours open will likely be a challenge for many food banks, as a lack of resources can dictate the number of hours a location can be open. Many food banks rely on volunteer labour, and will need to be sensitive of their volunteers' ability to take on more hours. Food banks will have to be mindful of the needs of volunteers when asking for more hours or later shifts. However, slight shifts to the hours of operation will allow for increased access for vulnerable clients, and make the food bank accessible to a wider array of people.

\section{Carpooling Database}

Several food banks mentioned that, when clients are new to the location, those without their own vehicle often struggle to find transportation. Once they have established a social network, however, clients are often able to arrange carpooling with friends from the food bank. Making this process accessible to clients from an early date would ease some of the transportation. This process could be as simple as a public sign-up sheet of people willing to drive other participants. Those in need of transportation could then be directed to any of the participants who have signed up to offer assistance. This system would remove the food bank from the expense of liability insurance and organizing volunteers, while giving clients without cars an earlier opportunity to have access to carpooling. ${ }^{2}$

\footnotetext{
2 While food bank volunteers have background checks done routinely, participants are not usually screened. The carpooling system may mean an increased risk for those involved, and each individual food bank would need a strategy to mitigate risks in their particular location.
} 
Although informal, clients' current carpooling system is based on developing social networks among participants, a key part of strengthening the community through social capital. ${ }^{3}$

Formalizing this process will allow new clients to access carpooling resources from the start of their

\section{Best Practices}

\section{Tomato Ladies, Oakville Fareshare Food Bank}

The Oakville Fareshare food bank, run almost exclusively on volunteer labour, noticed that many of its newcomer clients were unsure how to use some of the ingredients they were being given by the food bank. To help participants ease into using the new food, some of the volunteers founded a program called the Tomato Ladies, which operates in a nearby community hub. Monthly cooking classes are offered free of charge, and participants take home simple, easy to repeat recipes using food typically distributed at the Oakville Fareshare Food Bank.

\section{The Table Community Food Centre}

Community Food Centres Canada uses a multipronged approach at fighting hunger, based off the success of The Stop Community Food Centre in Toronto, which has long been a leader in providing fresh, culturally appropriate food for participants. They focus on targeting programs and food towards the many diverse newcomer groups in their catchment area. In Perth, Ontario, The Table has established a delivery service for participants, who can call in an order during set times of the week. In maintaining participant access hours during weekdays and evenings, the Table allows those who can access the Food Centre through their own private transportation to do so, while providing a formalized process for those who are unable to come to the Centre independently. time with the food bank. Encouraging those who have access to a vehicle to help those who do not will help to reduce barriers for clients and increase social capital in the community.

\section{Unfamiliar Food}

Food banks reported that many newcomers were unfamiliar with the food provided by food banks. There are short-term and long-term ways to address this challenge. In the short term, it will likely be difficult to change the types of food that food banks receive, particularly if they operate on a model of food donations from neighbours and grocery stores. However, food banks can try to teach newcomers simple ways to cook with some of the ingredients included in the basket, through demonstrations or classes.

In the long term, food banks can work towards changing the types of food they are requesting. They can gain an understanding of priorities by initiating conversations with newcomer clients, asking them what their food staples are, and what types of food they would

\footnotetext{
${ }^{3}$ Social capital is a highly contested term. This paper draws from Robert Putnam, who defined social capital as the connections and relationships that people form, which can help develop trust and co-operation in a community.
} 
prioritize for a basket. In this way, the food bank will start to gain an understanding of the needs of their clients, and could tailor their own purchasing to meet those needs. The OAFB may be another avenue to work towards providing culturally appropriate food throughout the region, removing the burden of sourcing food from individual food banks, and onto a larger institution. In addition, individual food banks can ask for monetary donations instead of food donations to allow them to purchase culturally appropriate food. 


\section{Chapter 8: Conclusion}

The built form, separation of land uses, and transportation systems in GTA suburbs make it challenging for low-income residents to move around their neighbourhoods without access to a car. Food banks are often unable to cover the costs of a delivery service, and those far from transit struggle to find other solutions to help clients reach them. As a result, clients who do not have access to a car resort to a patchwork of transportation methods, depending on the resources available to them at the time.

Although poverty in the suburbs has always been present, it is now growing at an alarming rate, with core housing need and the number of children in poverty rising rapidly. Food bank clients include newcomers trying to establish themselves in Canada, workers who have been recently unemployed, seniors on fixed incomes, as well as the working poor. The hidden nature of poverty in the suburbs means that the public does not know as much about it as they do about urban poverty.

The suburbs have not been planned to deal with issues of poverty. They are designed almost exclusively for the car, and suburban public transit aims to facilitate commuting, rather than trips that take place during the day. The lack of welcoming public realm or active transportation infrastructure in suburbs means that walking or cycling are not attractive options. Social services are often placed in centrally-located malls that may be hard to get to for residents without cars, which leaves low-income residents dependent on infrequent and unreliable transportation or their support network in order to gain access to the services they require. These options, and in particular public transit, are not ideal for food bank participants, who must carry groceries home after an appointment, and may also need to bring their children with them for the visit.

In conducting the research for this paper, I visited the two transit-accessible sample locations. In order to gain an understanding of what it meant to navigate suburban areas without access to a car, I chose to use public transit to travel there, making the trip to these locations during February and March. I used a combination of GO trains (commuter rail) and bus transit systems to arrive at each location.

Despite the proximity to transit of both locations, I still had to walk a few blocks to arrive at both food banks. Sidewalks were not adequately cleared, as pedestrian accessibility is not a high priority in these areas. Snow-covered sidewalks were difficult to navigate, even without heavy bags of food to carry or transport in a bundle buggy. While planning ahead to arrive on time, I had to give myself ample time cushions; missing one bus might mean waiting $\mathbf{2 0}$ minutes or more for the next one. 
On leaving one location in particular, I had to wait for 35 minutes along an industrial parkway, with no bus shelter, for a bus to arrive.

I have the privilege of living in a city with a well-planned transportation system, where I can choose to access buses, streetcars or subway lines to arrive at my destination. While it was an inconvenience for me to take transit to these two food banks, it was a minor one - I was free to leave that municipality and return to my own. Low-income suburban residents who do not have access to a car do not have this freedom; they must navigate a transportation system that is not designed to meet their needs. Social service providers, and in particular food banks, have a responsibility to think creatively about their participants' needs, and try to find solutions that ease the transportation barrier. But this work cannot rest on their shoulders alone.

Suburban municipalities and the planners who assist and advise them have a duty to consider the needs of all residents when planning their future growth. Planning a municipality that forces residents to drive actively reduces the mobility not only of low-income residents, but also of children and seniors. Better-planned transportation will not only allow residents to access food banks and other social services, it will enable them to participate fully in their neighbourhood and their city. 


\section{Appendix A: Interview Questions}

Interview Questions: Manager

Themes: Identification of barriers; evaluation of current programs/policies; success and challenges of programs currently in place; plans for future programs; support needed from external sources

1. Do you collect data on food bank clients?

2. How many people do you provide support to in a month/year?

3. What are some challenges that clients face in trying to reach the food bank?

4. How has the organization worked to overcome these challenges?

5. Describe any positive or negative feedback you have heard about getting to the food bank.

6. Describe any strategies you have used to reduce any challenges to getting to the food bank.

7. How has the food bank worked to increase access (cultural difference, age, transportation)?

8. What are you doing to improve access to transportation?

9. Are these strategies longstanding or are have they recently been put in place?

10. Are these strategies successful? Could you describe how they are successful?

11. Are there any plans for future programs that will build on the progress of successful programs?

Interview Questions: Front Line Worker

Themes: How clients navigate barriers to accessing food bank; how clients have responded to current programs in place; any suggestions that front line workers have for future programming; any suggestions that clients have made about programming

1. How often are you in the food bank?

2. What tasks do you perform in the food bank?

3. How do most people travel to the food bank?

4. How do people carry their food basket home?

5. Do they have difficulties getting to wherever they are going once they have collected their food?

6. In the time you have been with the food bank, has the typical food bank user changed?

7. Are there more families/different ages/different cultural backgrounds coming into the food bank?

8. Have you heard clients speaking about problems they have had in reaching the food bank?

9. Are there any suggestions you have for helping clients reach the food bank? 
Appendix B: Word Cloud Sample

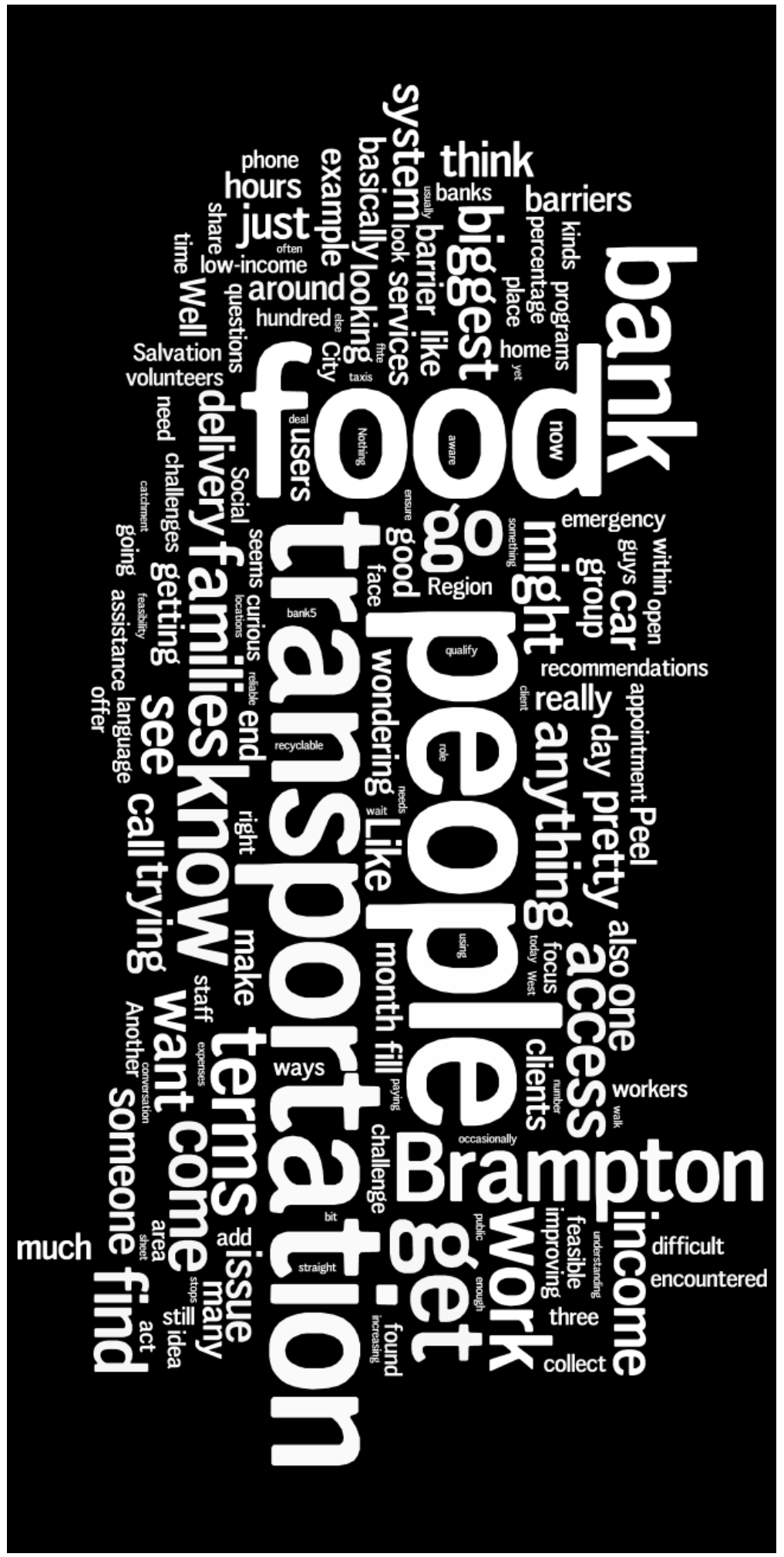


Appendix C: Food Banks of the GTA

\begin{tabular}{|c|c|c|c|c|}
\hline Name & Region & OAFB Member & Days Open/Week & Website \\
\hline Caledon Community Services & Peel & Yes & 5 & Yes \\
\hline The Salvation Army Brampton Food Bank & Peel & Yes & 5 & Yes \\
\hline Seva Food Bank & Peel & No & 3 & Yes \\
\hline Seva Food Bank & Peel & No & 3 & Yes \\
\hline St. Mary's Food Bank & Peel & No & 3 & Yes \\
\hline St. Mary's Food Bank & Peel & No & 3 & Yes \\
\hline Salvation Army Erin Mills & Peel & No & 3 & Yes \\
\hline Compass Market Food Bank & Peel & No & 3 & Yes \\
\hline LifeCorps Foodshare & York & Yes & 0 & Yes \\
\hline Aurora Food Pantry & York & No & 1 & No \\
\hline Mount Albert Food Pantry & York & No & 1 & No \\
\hline Georgina Community Food Pantry & York & No & 2 & No \\
\hline King Township Food Bank & York & No & 0 & Yes \\
\hline Markham Food Bank & York & No & 3 & Yes \\
\hline Newmarket Food Pantry & York & No & 3 & No \\
\hline Richmond Hill Community Food Bank & York & No & 5 & Yes \\
\hline Humanity First & York & No & 0 & Yes \\
\hline Vaughan Food Bank & York & No & 2 & Yes \\
\hline Whitchurch-Stouffville Food Bank & York & No & 1 & No \\
\hline Food for Life - Refresh Foods & Halton & Yes & 5 & Yes \\
\hline Partnership West Family Support & Halton & Yes & 4 & Yes \\
\hline Hamilton Food Share & Halton & Yes & 0 & Yes \\
\hline Acton Foodshare & Halton & No & 1 & Yes \\
\hline Salvation Army & Halton & No & 0 & No \\
\hline Oakville Fareshare Food Bank & Halton & No & 2 & Yes \\
\hline Georgetown Breadbasket & Halton & No & 2 & Yes \\
\hline Kerr Street Ministries & Halton & No & 5 & Yes \\
\hline Salvation Army & Halton & No & 0 & Yes \\
\hline Partnership West & Halton & No & 4 & Yes \\
\hline Salvation Army Khi Community & Halton & No & 3 & Yes \\
\hline Uxbridge Loaves and Fishes Food Bank & Durham & Yes & 1 & No \\
\hline Feed the Need in Durham & Durham & Yes & 0 & Yes \\
\hline Clarington East Food Bank & Durham & Yes & 2 & Yes \\
\hline St Paul's on-the-Hill Community Food Bank & Durham & No & 2 & Yes \\
\hline Helping Hands & Durham & No & 0 & Yes \\
\hline Brock Community Food Bank & Durham & No & 0 & Yes \\
\hline Salvation Army & Durham & No & 2 & No \\
\hline Claremont United Church & Durham & No & 0 & No \\
\hline Clarington East Food Bank & Durham & No & 2 & No \\
\hline Simcoe Hall Settlement House & Durham & No & 5 & No \\
\hline
\end{tabular}




\begin{tabular}{lllll} 
Seventh Day Adventists & Durham & No & 2 & No \\
St Peter's Anglican Church Food Bank & Durham & No & 1 & No \\
Salvation Army Family Services & Durham & No & 0 & No \\
Zion Hope Food Bank & Durham & No & 1 No \\
Operation Scugog & Durham & No & 1 No \\
Salvation Army & Durham & No & 4 No \\
\hline
\end{tabular}




\section{Bibliography}

Blais, P. (2010). Perverse Cities. Vancouver: UBC Press.

City of Mississauga. (2013). Population, demographics \& housing. City of Mississauga.

City of Toronto. (2011). Toronto Regional Housing Data Bank. Toronto: Civic Action.

CMHC. (2010). Housing in Canada Online. Retrieved from Canadian Mortgage and Housing Corporation:

http://cmhc.beyond2020.com/HiCODefinitions_EN.html\#_Core_Housing_Need_Status

CMHC. (2013). Canadian Housing Observer. Canada Mortgage and Housing Corporation.

Daily Bread Food Bank. (2013). Who's Hungry: A Tale of Three Cities. Toronto.

Dreier, P. (2004). Poverty in the Suburbs. Nation, 6-7.

Dunham-Jones, E., \& Williamson, J. (2011). Retrofitting Suburbia. Hoboken: Willey.

Edmonton's Food Bank. (2013). History. Retrieved from Edmonton's Food Bank: http://edmontonsfoodbank.com/about/history/

Erwing, R., Pendall, R., \& Chen, D. (2002). Measuring sprawl and its impact. Smart Growt America.

Fairclough, N. (1995). Critical discourse analysis: the critical study of language. London: Longman.

Filion, P. (2003). Towards smart growth? The difficult implementation of alternatives to urban disperson. Canadian Journal of Urban Research, 48-70.

Fincher, R. (1999). New Geographies of Disadvantage: Implications for Service Delivery. Australian Journal of Public Administration, 55-60.

Food Banks of Canada. (2013). Hunger Count.

Forsyth, A., Oakes, J., Schmitz, K., \& Hearst, M. (2007). Does residential density increase walking and other physical activity? Urban Studies, 679-697.

Francis, L., Berger, C., Giardini, M., Steinman, C., \& Kim, K. (2009). Pregnant and Poor in the Suburb. Journal of Sociology and Welfare, 133-157.

Francis, L., Berger, C., Giardini, M., Steinman, C., \& Kim, K. (2009). Pregnant and poor in the suburbs: The experiences of economically disadvantaged women of color with prenatal services in a wealthy suburban county. Journal of Sociology and Social Welfare, 133-157.

Garreau, J. (1991). Edge Citiy. New York City: Doubleday.

Gilliam, D., \& Dewar, H. (1964). Suburbs share the cross of poverty. The Washington Post, E1-2.

Hulchanski, D. (2006). The three cities within Toronto. Toronto: University of Toronto. 
Hunter, G., Sanchez, M., \& Douglas, F. (2012). Incomes of the one per cent (and everyone else) in Canada. Regina: University of Regina.

Huq, R. (2007). The sound of the suburbs. Soundings, 35-44.

Kitchen, H. (2002). Municial Revenue and Expenditure Issues in Canada. Canadian Tax Foundation.

Lakey, J. (2014, January 11). Pickering's huge Seaton development clears final hurdle. Retrieved from Toronto Star: http://www.thestar.com/news/gta/2014/01/11/pickerings_huge_seaton_development_c lears_final_hurdle.html

Lee, B., \& Hall, M. (2010). How diverse are US suburbs? Urban Studies, 3-28.

Lee, S., \& Leigh, N. G. (2005). The role of inner-ring suburbs in metropolitan smart growth strategies. Journal of Planning Literature, 330-346.

Lugina, H., Christennson, K., Mbekenga, C., \& Olsson, P. (2010). Postpartum experiences of firsttime fathers in a Tanzanian suburb: A qualitative interview study. Midwifery, 174-180.

Madden, J. (2003). The changing spatial concentration of income and poverty among suburbs of large US metropolitan areas. Urban Studies, 481-503.

McManus, R., \& Ethington, P. (2007). Suburbs in transition: new approaches to suburban history. Urban History, 317-337.

Ministry of Finance. (2013). Ontario Population Projections Update. Toronto: Queen's Park Printer for Ontario.

Ministry of Infrastructure. (2006). Growth Plan for the Greater Golden Horseshoe. Toronto: Government of Ontario.

Muzzio, D., \& Halper, T. (2002). Pleasantville? The suburb and its representation in American movies. Urban Affairs Review, 543-574.

Nosal, B. (2009). Creating walkable and transit-supportive comunities in Halton. Halton: Halton Region Health Department.

OAFB. (2012). How to become a member. Retrieved March 6, 2014, from Ontario Association of Food Banks: http://www.oafb.ca/how-to-become-a-member-2

Preston, V., \& Lo, L. (2000). Asian theme malls in suburban Toronto: land use conflict in Richmond Hill. Canadian Geographer, 182-190.

Preston, V., Murdie, R., Wedlock, J., Agrawal, S., Anucha, U., D'Addario, S., \& Kwak, M. (2009). Immigrants and homlessness: At risk in Canada's outer suburbs. The Canadian Geographer, 288-304.

Rodriguez, D., Evenson, K., Brines, S., \& Diez Roux, A. (2009). Land use, residential density, and walking. American Journal of Preventative Medicine, 397-404. 
Saul, N., \& Curtis, A. (2013). The Stop: How the fight for good food transformed a communiy and inspired a movement. U.S.A.: Random House Canada.

Scharf, K., Saul, N., \& Levkoe, C. (2010). In every community a place for good food. Toronto: Metcalf Foundation.

Sewell, J. (2009). The shape of the suburbs. Toronto: University of Toronto Press.

Social Planning Network of Ontario. (2012). Action on Poverty. Toronto: Social Planning Toronto.

Social Planning Toronto. (2012). Action on Poverty Report. Toronto.

Stapleton, J., Murphy, B., \& Xing, Y. (2012). The 'Working Poor' in Toronto Region: Who they are, where they live, and how trends are changing. Toronto: Metcalf Foundation.

Statistics Canada. (2012). Census Metropolitan Area of Toronto. Retrieved from Focus on Geography Series: http://www12.statcan.gc.ca/census-recensement/2011/as-sa/fogsspg/Facts-cma-eng.cfm?LANG=Eng\&GK=CMA\&GC=535

Statistics Canada. (2014, 01 31). Product Main Page. Retrieved from Low Income After Tax: http://www5.statcan.gc.ca/bsolc/olc-cel/olc-cel?catno=13-592-X\&lang=eng

Suro, R., Wilson, J., \& Singer, A. (2011). Immigration and Poverty in America's Suburbs. Brookings Institute.

Teaford, J. (2008). The American Suburb. New York: Routledge.

Transportation Cooperative Research Program. (1999). Guidelines for enhancing suburban mobility using public transportation. Washington, D.C.: Transportation Research Board.

Welsch, J., \& MacRae, R. (1998). Food Citizenship and Community Food Security . Toronto: Toronto Food Policy Council. 